\title{
Spectral cumulus parameterization based on cloud-resolving model
}

\author{
Yuya Baba' ${ }^{1}$ D \\ Received: 7 November 2017 / Accepted: 12 February 2018 / Published online: 20 February 2018 \\ (c) The Author(s) 2018. This article is an open access publication
}

\begin{abstract}
We have developed a spectral cumulus parameterization using a cloud-resolving model. This includes a new parameterization of the entrainment rate which was derived from analysis of the cloud properties obtained from the cloud-resolving model simulation and was valid for both shallow and deep convection. The new scheme was examined in a single-column model experiment and compared with the existing parameterization of Gregory (2001, Q J R Meteorol Soc 127:53-72) (GR scheme). The results showed that the GR scheme simulated more shallow and diluted convection than the new scheme. To further validate the physical performance of the parameterizations, Atmospheric Model Intercomparison Project (AMIP) experiments were performed, and the results were compared with reanalysis data. The new scheme performed better than the GR scheme in terms of mean state and variability of atmospheric circulation, i.e., the new scheme improved positive bias of precipitation in western Pacific region, and improved positive bias of outgoing shortwave radiation over the ocean. The new scheme also simulated better features of convectively coupled equatorial waves and Madden-Julian oscillation. These improvements were found to be derived from the modification of parameterization for the entrainment rate, i.e., the proposed parameterization suppressed excessive increase of entrainment, thus suppressing excessive increase of low-level clouds.
\end{abstract}

Keywords Cumulus parameterization $\cdot$ Cloud-resolving model $\cdot$ Entrainment rate

\section{Introduction}

The cumulus parameterization is responsible for reproducing tropical convection, and thus convectively coupled equatorial waves (CCEWs) and Madden-Julian oscillation (MJO; Madden and Julian 1971) which play important roles in global atmospheric circulation. Simulations of these phenomena are still considered difficult for even recent general circulation models (GCMs), since they involve a lot of unresolved cloud-related processes and still contain many uncertainties (e.g., Kim et al. 2009; Weaver et al. 2011). However, recent analysis on results from GCMs revealed that improvements were found compared with past GCMs due to the updates in cumulus parameterizations (Hung et al. 2013). Regardless of the formulation in the parameterizations, the updates are commonly related to the representation of unresolved cloud properties, especially vertical profile of

Yuya Baba

babay@jamstec.go.jp

1 Application Laboratory, Japan Agency for MarineEarth Science and Technology, 3173-25, Showa-machi, Kanazawa-ku, Yokohama 236-0001, Japan convective clouds, e.g., diluted convective updraft relating to entrainment and convective momentum transport. Therefore, modeling procedures for unresolved cloud properties are considered key to improving the physical performance of cumulus parameterization.

Although considering detailed unresolved cloud properties was found to be important for improvement, some problems remain in their modeling. One problem is that cumulus parameterization must consider and express different cloud types in its parameterization. To overcome this, some cumulus parameterizations were used with a shallow convection scheme (e.g., Park and Bretherton 2009; Zhang and Song 2009). In contrast, some cumulus parameterizations were developed so that the parameterizations could model both deep and shallow convection using selective frameworks (e.g., Tiedtke 1989; Bechtold et al. 2008, 2014) or generalized frameworks (e.g., Arakawa and Schubert 1974; Chikira and Sugiyama 2010; Yoshimura et al. 2015). In reality, deep and shallow convection can coexist, and thus the parameterization should be able to express not only different cloud types but also their coexistence. Unfortunately, the best approach to expressing this coexistence has not yet been determined. 
Another problem is that an in-cloud parameterization that models a detailed unresolved convective cloud structure has not yet been established. One of the most important incloud parameterizations is entrainment rate, and several past studies proposed different parameterizations (e.g., Nordeng 1994; Grant and Brown 1999; Gregory 2001; Neggers and Siebesma 2002; Zhang et al. 2016). In particular, based on cloud-resolving model (CRM), Gregory (2001) developed a parameterization that modeled the entrainment rate with in-cloud quantities, and it has been known to work well in cumulus parameterization and analysis on in-cloud properties (e.g., Del Genio et al. 2007; Chikira and Sugiyama 2010; Del Genio and Wu 2010). However, noting that the parameters are different for deep and shallow convection, the model coefficients for entrainment rate showed inconsistency for different cloud types (Gregory 2001) or different altitudes (Del Genio and Wu 2010). Based on CRM simulation, Zhang et al. (2016) recently proposed parameterization for entrainment rate using in-cloud vertical velocity. The model coefficients of their parameterization also showed dependence on the altitude. These are likely because incloud properties were parameterized based only on analysis of few convective clouds' structure in short time scale (e.g., the time scale was limited to several hours), and thus lacked generality to express different cloud types. In more realistic cases, various kinds of clouds appear in various time scales, and so in-cloud properties should be parameterized using statistical long-range analysis to obtain more generalized parameterization.

The purpose of this study is to propose a generalized in-cloud parameterization which can be implemented into cumulus parameterization using CRM, and to evaluate the validity of cumulus parameterization employing the in-cloud parameterization in simulation of global atmospheric circulation. Using CRM, a parameterization for in-cloud properties relating to entrainment rate is introduced. Long-range CRM simulation is performed to analyze statistical in-cloud properties and to develop a generalized in-cloud parameterization. To treat a variety of different cloud types and express their coexistence in coarse resolution, we consider a spectral approach (e.g., Arakawa and Schubert 1974) rather than the bulk mass flux approach (e.g., Tiedtke 1989; Gregory and Rowntree 1990), and we adopted it to the cumulus parameterization.

Section 2 summarizes formulations for existing in-cloud parameterizations. New formulations for the in-cloud parameterization are presented in Sect. 3 by performing CRM simulation and statistical analysis on the convective cloud structure. In Sect. 4, the spectral cumulus parameterization is constructed, and the formulations are provided. Fundamental properties of the developed cumulus parameterization are examined using a single-column model (SCM) experiment, and the results are presented in Sect. 5. To validate the developed parameterization, Sect. 6 compares the results of Atmospheric Model Intercomparison Project (AMIP) experiments using the proposed and existing parameterizations, and reanalysis data are used for the validation. Section 7 gives a summary and conclusion.

\section{Formulations for in-cloud properties of convective updraft}

\subsection{Cloud mean updraft velocity equation}

The cloud mean updraft velocity equation is commonly used to diagnose in-cloud updraft velocity in parameterizations of convective clouds, and the diagnosed velocity is also used to model in-cloud quantities. The cloud mean updraft velocity equation is given as (Gregory 2001):

$\frac{1}{2} \frac{\partial \bar{w}^{c 2}}{\partial z}=\bar{B}^{c}-\frac{1}{\sigma \rho}\left(\frac{\partial \sigma \rho{\overline{w^{\prime 2}}}^{c}}{\partial z}\right)-\frac{1}{\rho}{\overline{\left(\frac{\partial p^{\prime}}{\partial z}\right)}}^{c}-g{\overline{\left(\frac{p^{\prime}}{\bar{p}}\right)}}^{c}-\epsilon \bar{w}^{c 2}$,

where $w$ is the updraft velocity, $\sigma$ is the fractional cloud area, $\rho$ is the density, $g$ is the gravitational acceleration, $p$ is the pressure, $\epsilon$ is the entrainment rate. Overbar and prime indicate hydrostatic basic state and deviation from the basic state, respectively, and ${ }^{-c}$ indicates the value is averaged over cloudy areas. Since Eq. (1) takes a complicated form, past studies have attempted to simplify the equation to estimate cloud mean updraft velocity. Simpson and Wiggert (1969) suggested following to estimate vertical variation of cloud mean updraft velocity:

$\frac{1}{2} \frac{\partial \bar{w}^{c 2}}{\partial z}=\frac{1}{\gamma+1} \bar{B}^{c}-\beta C_{d} \epsilon \bar{w}^{c 2}-\epsilon \bar{w}^{c 2}$,

where $\gamma$ is the parameter to account for the turbulence effect on buoyancy, $\beta C_{d}$ is the parameter to account for the effect of pressure perturbation terms. Recent studies (e.g., Nordeng 1994; Bretherton et al. 2004; Chikira and Sugiyama 2010) employed a more simplified form:

$\frac{1}{2} \frac{\partial \bar{w}^{c 2}}{\partial z}=a \bar{B}^{c}-\epsilon \bar{w}^{c 2}$,

where the effects of turbulence and pressure perturbation are considered in the buoyancy term using a parameter $a$. On the other hand, Gregory (2001) employed a modified Eq. (2) given as:

$\frac{1}{2} \frac{\partial \bar{w}^{c 2}}{\partial z}=a \bar{B}^{c}-b \delta \bar{w}^{c 2}-\epsilon \bar{w}^{c 2}$,

where detrainment rate $\delta$ is used with a parameter $b$. This formulation is different from Eq. (3) as the effect of pressure perturbation is modeled as a drag term using detrainment 
rate rather than entrainment rate as in Eq. (2). Equation (3) or (4) is used to estimate the updraft velocity which is used to parameterize in-cloud quantities in cumulus parameterizations. This study focused on the in-cloud parameterization for entrainment rate using the updraft velocity as described below. Hereafter, in-cloud values are denoted by subscripts $u$ (for updraft) and $d$ (for downdraft) for simplicity.

\subsection{Entrainment rate of convective updraft}

The entrainment rate $\epsilon_{u}$ and detrainment rate $\delta_{u}$ are key variables for cumulus parameterization as they determine the lateral mixing rate between clouds and environmental air, and thus cloud mass flux. Updraft cloud mass flux $M_{u}$ is related to entrainment and detrainment as follows (e.g., Tiedtke 1989; Rooy et al. 2013):

$\frac{\partial M_{u}}{\partial z}=E_{u}-D_{u}=\epsilon_{u} M_{u}-\delta_{u} M_{u}$,

where $z$ is the vertical coordinate, $E_{u}$ and $D_{u}$ are updraft entrainment and detrainment, respectively. The equation means that cloud mass flux increases vertically as the entrainment increases and decreases as the detrainment increases.

One approach for modeling entrainment rate is to model the value using only environmental quantities (e.g., Gregory and Rowntree 1990; Bechtold et al. 2008; Yoshimura et al. 2015). Alternatively, some approaches employed in-cloud quantities as the diagnostic parameters to estimate the entrainment rate. Neggers and Siebesma (2002) proposed the following formulation of entrainment rate for shallow convection:

$\epsilon_{u}=\frac{\mu}{\tau_{c}} \frac{1}{w_{u}}$,

where $\tau_{c}$ and $\mu$ are turnover time scale and calibration parameter, respectively. Nordeng (1994) proposed the following equation for entrainment rate by integrating the cloud mean updraft velocity equation and using in-cloud buoyancy:

$\epsilon_{u}=\frac{B_{u}}{2\left(w_{b}^{2}+\int_{z_{b}}^{z_{t}} B_{u} d z\right)}$,

where $w_{b}$ is the cloud base updraft velocity, $B_{u}$ is the incloud buoyancy, $z_{b}$ is the cloud base height, $z_{t}$ is the cloud top height. Gregory (2001) proposed a model of entrainment rate that assumes the reduction of in-cloud buoyancy is derived from entrainment with the following formulation:

$\epsilon_{u}=\frac{a C_{\epsilon} B_{u}}{w_{u}^{2}}$

where $a=1 / 6$ and $C_{\epsilon}$ are model parameters derived from the relationship of terms in the cloud mean updraft velocity equation. Although Eqs. (7) and (8) have different forms, their only difference is whether the cloud mean updraft velocity is vertically integrated; the essential relationship between buoyancy and entrainment is considered identical, i.e., the entrainment rate is defined as a function of in-cloud buoyancy and cloud mean updraft velocity. It should be noted here that Eqs. (7) and (8) require $w_{u}$, which is obtained from Eqs. (3) or (4), and thus $w_{u}$ is an important quantity for computing the entrainment rate in these parameterizations.

Parameterizing entrainment rate using in-cloud quantities seems to be more accurate than parameterizing only from environmental values, since the value of entrainment rate depends not only on environment but also on the states of convective clouds (Gregory 2001). However, using these parameterizations for various cloud types is problematic. For instance, Eq. (6) is proposed only for shallow convection. Nordeng (1994) used Eq. (7) only for deep convection. In Eq. (8), the value of $C_{\epsilon}$ is dependent on cloud types as $C_{\epsilon}=0.5$ for shallow convection and $C_{\epsilon}=0.25$ for deep convection (Gregory 2001). Chikira and Sugiyama (2010) used this formulation in cumulus parameterization, but the choice of the value of $C_{\epsilon}$ lacked a physical basis. Del Genio and $\mathrm{Wu}(2010)$ showed that the value is not constant for the different altitudes in the convective clouds. However, they indicated that the values of $C_{\epsilon}$ were identical for different cloud types with different cloud depths.

As discussed here, applying these parameterizations remains problematic as they lacked generality for different cloud types. Therefore, using long-range CRM simulation, an improved parameterization is discussed and proposed in the following section. In particular, we focus on Eq. (8) since the in-cloud parameterization can be extended for different cloud types as noted in Del Genio and Wu (2010).

\section{CRM experiment}

\subsection{Experimental setup and analysis procedure}

The experimental setup for the long-range CRM simulation follows the convective radiative quasi-equilibrium (CRQE) experiment designed to mimic global atmospheric energy budget (Grabowski 2006; Baba 2015). The configurations of CRQE experiment are characterized by zonal wind forcing, incoming shortwave radiation of $342 \mathrm{~W} \mathrm{~m}^{-2}$, ground (sea) surface properties such as surface albedo (set to 0.15) and surface temperature (set to $288 \mathrm{~K}$ ). A nonhydrostatic atmospheric model which has been validated in both realistic and idealized experiments (Baba et al. 2010; Baba and Takahashi 2013, 2014; Baba 2015, 2016) is employed for the present CRM simulation. A simplified 3-class one-moment microphysics (Grabowski 1998) is employed as cloud microphysics. The other physical parameterizations are identical 
to those employed in Baba (2015). The horizontal size of the domain is $200 \mathrm{~km}$, and a periodic boundary condition is applied to the horizontal direction. The model top is set to $24 \mathrm{~km}$. The time integration is performed for 120 days.

The resolution of CRM that simulates deep convection must be higher than that of normal CRM (1-2 km resolution) when the entrainment is measured (e.g., Kuang and Bretherton 2006; Romps 2010). However, due to the limitation of computational resources, very fine resolution, such as $100 \mathrm{~m}$ or finer, cannot be applied to the present long-range CRM simulation. Khairoutdinov et al. (2009) discussed resolution dependence of simulated properties of deep convection, and showed that statistics of deep convection converged with resolution finer than $1600 \mathrm{~m}$, but updraft-core profiles only converged with resolution finer than $200 \mathrm{~m}$. Del Genio and $\mathrm{Wu}$ (2010) investigated in-cloud properties using 600 and $125 \mathrm{~m}$ horizontal resolutions and found that qualitatively similar trends could be obtained for the profiles of in-cloud quantities even with $600 \mathrm{~m}$ resolution. Based on the finding, the horizontal resolution of this experiment was set to 600 $\mathrm{m}$. Total 62 vertical layers were used and the vertical resolution was set to be finer than $600 \mathrm{~m}$ below the $12 \mathrm{~km}$ height.

The procedure of analysis to parameterize in-cloud properties is as follows. The convective clouds are extracted from the results of experiment by the cloud partitioning method of Xu (1995). This method can identify convective clouds using three criteria relating to convective cloud properties, i.e., the convective clouds are identified when (1) updraft velocity of the cloud below the melting level is larger than those in adjacent region, or (2) the maximum updraft velocity exceeds $3 \mathrm{~m} \mathrm{~s}^{-1}$, or (3) precipitation exceeds $25 \mathrm{~mm} \mathrm{~h}^{-1}$. Then, convective cloud columns including both deep and shallow convection can be identified, excluding non-convective cloud (stratiform clouds and dry convection) columns. The convective clouds are then categorized into deep and shallow clouds to obtain representative statistical convective cloud structures. The threshold for identifying deep convection is that the cloud top height reaches $500 \mathrm{hPa}$ height; otherwise, the convective column is identified as a shallow convection. After identifying convective column, the cloudy area was identified by positive updraft velocity and total cloud condensate larger than $1 \times 10^{-5} \mathrm{~kg} \mathrm{~kg}^{-1}$.

Entrainment and detrainment used to be measured using the traditional tracer budget method (e.g., Siebesma and Cuijpers 1995), which is hard to conduct for the present experiment. This is because the traditional method analyzes the tracer budget for single convective cloud. However, in long-range CRM simulation, convective clouds appear and disappear during the integration, and thus it is hard to separate each tracer responding to each convective cloud and consequently hard to calculate their budgets. Therefore, the following methods were adopted instead. First, entrainment and detrainment are measured by the direct method of
Romps (2010), which does not require tracing the conserved variable and which measures the entrainment and detrainment using the local lateral air exchange rate between clouds and environmental air. However, this method is known to overestimate entrainment and detrainment compared to the traditional method (e.g., Dawe and Austin 2011; Rooy et al. 2013). To overcome this drawback, the transformation method used in Dawe and Austin (2011) was then adopted. This method converts the directly measured values of entrainment and detrainment into values as measured by the traditional method. For this conversion, total water was used as the conserved variable.

To extract statistical and representative convective cloud structures, conditional averaging was performed for simulated convective clouds during the last 30 days.

\subsection{Properties of convective clouds}

First, the statistical properties of simulated convective clouds are analyzed. Table 1 summarizes some statistics of the extracted convective clouds. The results show distinct differences for deep and shallow convective clouds, indicating that cloud base height, cloud top height, and maximum updraft velocity are greatly dependent on the cloud types. These are consistent with known features: for example, deep convection has a higher cloud base height and larger maximum cloud updraft velocity, and the values are comparable with those of preceding studies (e.g., Khairoutdinov and Randall 2002; von Salzen and McFarlane 2002). In addition, the occupation ratio of each cloud type is consistent with the features of original experiment as the experimental setup is likely to simulate more shallow convection (Grabowski 2006). In contrast to the above differences, the mean values of cloud base updraft velocity were found to be similar regardless of the difference in cloud types.

Cloud base updraft velocity (denoted as $w_{b}$ hereafter) is important for cumulus parameterization because the convective cloud structure is modeled by the cloud base mass flux (e.g., Pan and Randall 1998) or directly characterized

Table 1 Statistics of cloud properties in the CRQE experiment

\begin{tabular}{llll}
\hline & Deep convection & Shallow convection & Total \\
\hline$z_{b}(\mathrm{~km})$ & $2.25(1.35)$ & $0.65(0.43)$ & $0.98(0.97)$ \\
$z_{t}(\mathrm{~km})$ & $8.00(1.95)$ & $2.15(0.88)$ & $3.35(0.26)$ \\
$w_{b}\left(\mathrm{~m} \mathrm{~s}^{-1}\right)$ & $0.47(0.43)$ & $0.59(0.37)$ & $0.57(0.39)$ \\
$w_{\max }\left(\mathrm{m} \mathrm{s}^{-1}\right)$ & $8.02(3.69)$ & $3.51(1.80)$ & $4.43(2.95)$ \\
Occupation $(\%)$ & 20.4 & 79.6 & 100 \\
\hline
\end{tabular}

The values in the parenthesis indicate standard deviation

$z_{b}$ mean cloud base height, $z_{t}$ mean cloud top height, $w_{b}$ mean cloud base updraft velocity, $w_{\max }$ maximum cloud mean updraft velocity, occupation percentage of frequency of occurrence 
by the value of $w_{b}$ (e.g., Tiedtke 1989; Chikira and Sugiyama 2010). Generally, only one representative value of $w_{b}$ is assumed, and thus its unresolved distribution is not considered. The distribution from the results of the experiments are shown in Fig. 1. The values of $w_{b}$ were collected from the results of CRM simulation during last 30 days, and the frequency was calculated for the several bins of the values of $w_{b}$. The simulated $w_{b}$ showed spectral distribution, and the distributions vary depending on the cloud types, although their mean values are similar. The clear difference of the distribution is the value of $w_{b}$ which indicates the most frequent occurrence. The most frequent velocity of deep convection is smaller than that of shallow convection. Because the total number of shallow convection is much greater than that of deep convection, the total distribution of $w_{b}$ becomes similar to that of shallow convection.
Next, entrainment and detrainment are measured. Figure 2 shows the vertical profiles of these quantities for both deep and shallow convection. As the vertical profiles indicate, the peak and large values of entrainment are located in the lower altitudes, while those of detrainment are located in the higher altitudes. The features are common for both deep and shallow convection. Thus, in-cloud structure is considered to be determined by entrainment in the lower altitudes, but by detrainment in the higher altitudes. These trends are consistent with the results of preceding studies (e.g., Siebesma et al. 2003; Romps 2010).

Figure 3 compares vertical profiles of entrainment rates for deep and shallow convection. The vertical profiles show qualitatively good agreement with the results of Zhang et al. (2016) (in Fig. 8) for both shallow and deep convection. In Fig. 3, the large entrainment rate was
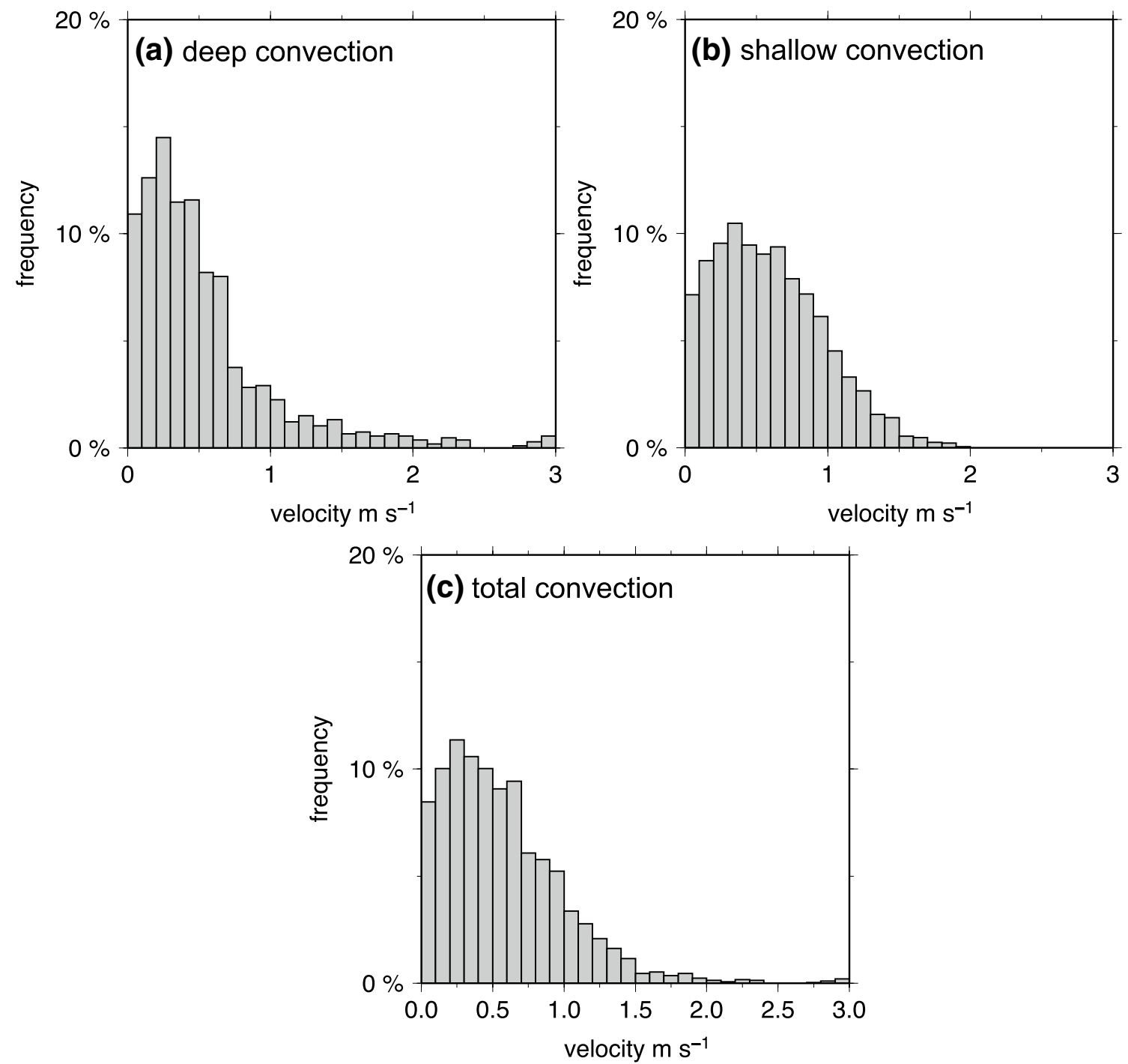

Fig. 1 Frequency histograms of cloud base updraft velocity for a deep convection, $\mathbf{b}$ shallow convection, and $\mathbf{c}$ total convection. The frequency is normalized by total number of convective columns 

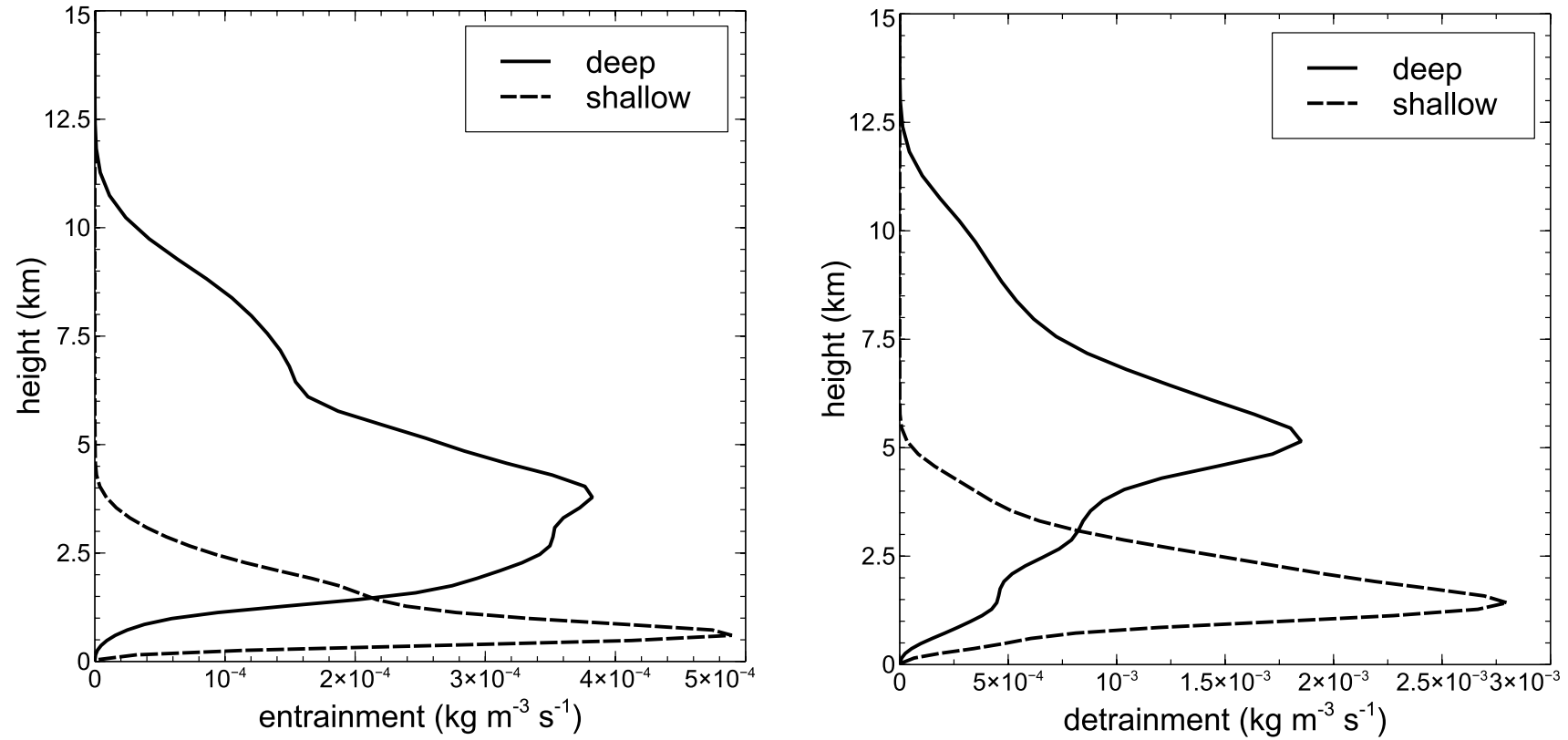

Fig. 2 Conditionally averaged vertical profiles of updraft entrainment $E_{u}=\epsilon_{u} M_{u}$ (left) and updraft detrainment $D_{u}=\delta_{u} M_{u}$ (right) for deep and shallow convection

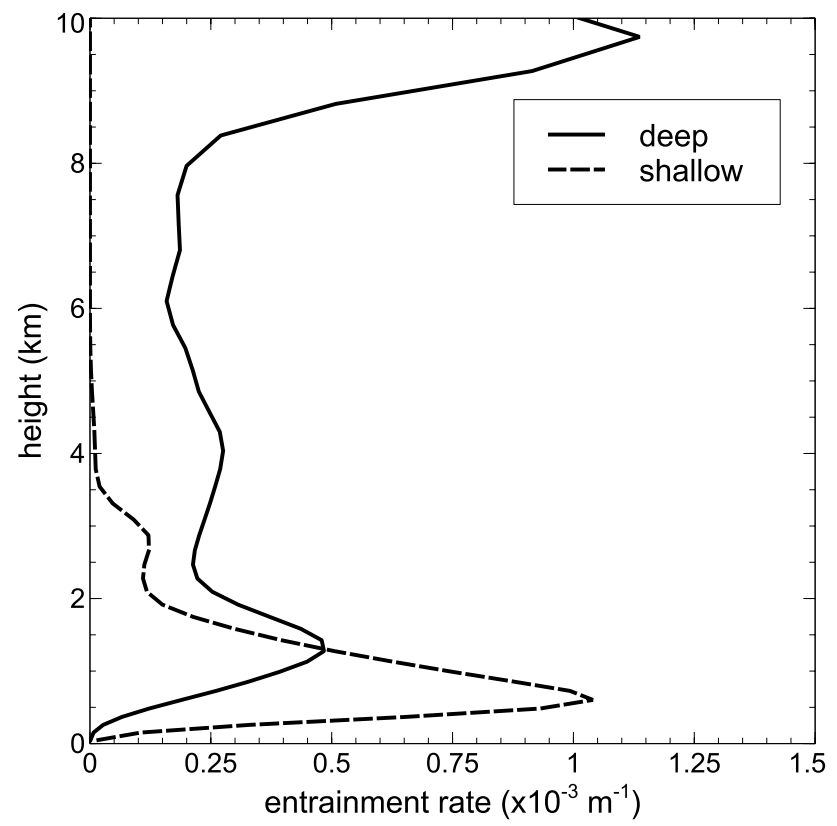

Fig. 3 Vertical profiles of updraft entrainment rates for deep and shallow convection

reproduced near the cloud top region of deep convection as cloud top entrainment, and this result is similar with that reproduced by Zhang et al. (2016). The maximum values of entrainment rate for deep and shallow convection are $0.5 \times 10^{-3} \mathrm{~m}^{-1}$ and $1.0 \times 10^{-3} \mathrm{~m}^{-1}$, respectively, except for the cloud top region of deep convection. The value for shallow convection is comparable with the value presented in Siebesma et al. (2003) but is smaller than their value $\left(2.0 \times 10^{-3} \mathrm{~m}^{-1}\right)$, this is because deeper convection than considered in Siebesma et al. (2003) is included in the conditionally averaged cloud properties. Several preceding studies showed that smaller entrainment rate for deep convection than that for shallow convection (e.g., Gregory 2001; Del Genio and Wu 2010), and this fact agrees with the present smaller entrainment rate for deep convection. Del Genio and Wu (2010) showed the vertical profiles of entrainment rate, and the present maximum value for deep convection is within the range of their values (approximately from $0.3 \times 10^{-3}$ to $2.0 \times 10^{-3} \mathrm{~m}^{-1}$ ).

A key relationship for the in-cloud quantities is the relative significance of buoyancy, entrainment and detrainment since these quantities dominate cloud mean updraft velocity and thus cloud mass flux. The in-cloud buoyancy is estimated by:

$B_{u}=g\left(\frac{T_{v, u}-\bar{T}_{v}}{\bar{T}_{v}}-l_{u}\right)$,

where $T_{v, u}$ is the in-cloud virtual temperature, $\bar{T}_{v}$ is the environmental virtual temperature which is obtained from horizontally averaged $T_{v}$ for whole domain excluding the cloudy area, $l_{u}$ is the in-cloud cloud condensate. The significances of each term appearing in Eq. (4) are compared in Fig. 4, which shows that buoyancy cannot be expressed by only entrainment term $\epsilon_{u} w_{u}^{2}$ near the cloud top region. This is inconsistent with the assumption in Gregory (2001) that the 


\section{(a) deep convection}

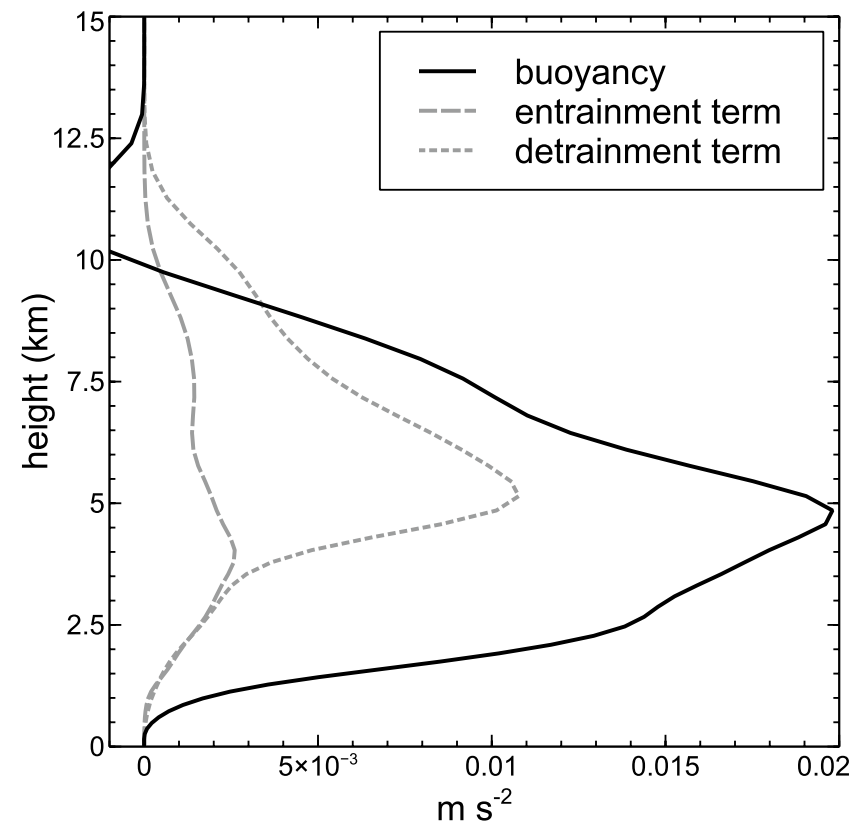

(b) shallow convection

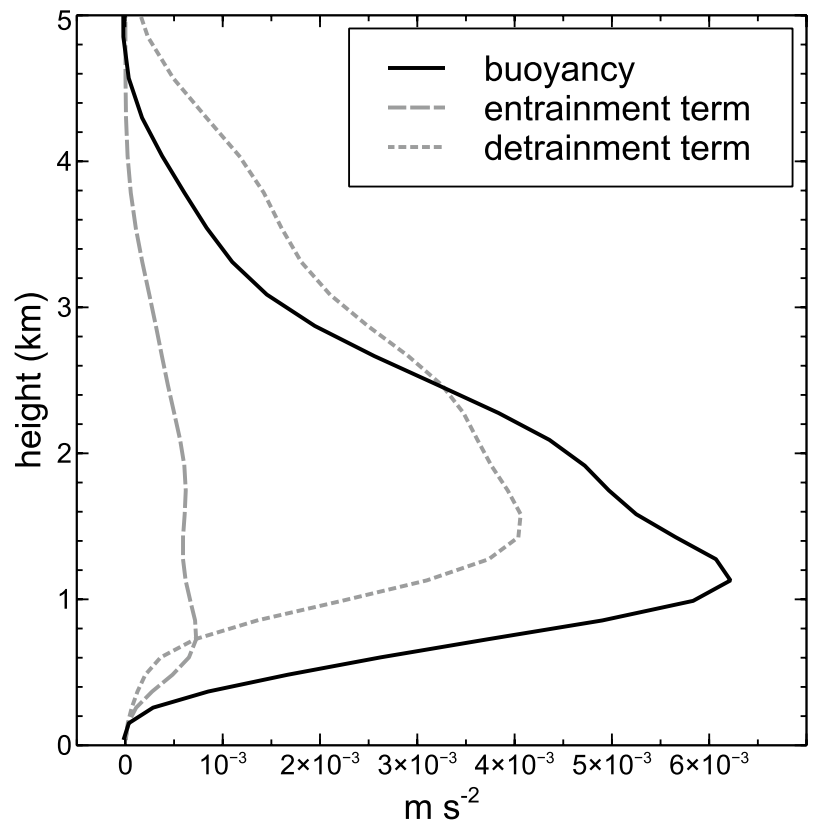

Fig. 4 Conditionally averaged vertical profiles of cloud mean buoyancy, entrainment and detrainment terms. Lines in the figure indicate buoyancy: $B_{u}$, entrainment: $\epsilon_{u} w_{u}^{2}$, and detrainment: $\delta_{u} w_{u}^{2}$

entrainment term is defined as a funcion of only buoyancy in Eq. (8). This is because Gregory (2001) did not investigate the correspondence between in-cloud buoyancy and the entrainment term, although he investigated the correspondence with other quantities. Contrary to the Eq. (8), the buoyancy remains large even in the upper altitude where the entrainment term decreases. In the higher altitudes, the detrainment term remains large, and thus the term seems to be related to the buoyancy decrease in the region.

\subsection{New formulations and estimation of parameters}

As indicated in the above analysis, the entrainment term could not approximate the profile of in-cloud buoyancy near the cloud top, and the value of entrainment term tends to decrease. This fact indicates that the parameterization of Gregory (2001) may be inappropriate for expressing entrainment in the region. To extend the parameterization of Gregory (2001) so that it can be applicable for whole cloudy regions with identical model parameters, the decrease of the entrainment term is required to be modeled. In Eq. (4), Gregory (2001) assumed that the detrainment term acts to reduce the effect of buoyancy on the increase in the cloud mean updraft velocity. In other words, when the updraft velocity decreases and thus buoyancy decreases, the detrainment acts to reduce the buoyancy if there is no entrainment. Considering this relationship, and assuming that remaining buoyancy which has been already reduced by the effect of entrainment is finally reduced by the effect of detrainment, the following equation can be led:

$\epsilon_{u} w_{u}^{2}=C_{1} B_{u}-C_{2} \delta_{u} w_{u}^{2}$,

where the value of entrainment term is limited to be positive (the minimum value is set to zero), and the detrainment term $\delta_{u} w_{u}^{2}$ is additionally considered compared to Eq. (8). $C_{1}$ and $C_{2}$ are the model parameters to be estimated. Estimations were performed for the model parameters so that relative residual error between left-hand and right-hand side (LHS and RHS) terms in Eq. (10) can become less than 15\%. Since the vertical profiles of entrainment term showed nonlinear profiles, least squares method did not provide good estimation especially for the profile at low altitude. Therefore, the estimation was performed so that the residual error at the low altitude can be minimum. Approximated values of $C_{1}$ and $C_{2}$ are $C_{1}=C_{2} \approx 0.2$, and they are found to be valid for both deep and shallow convection (Fig. 5), even though some deviations remain near the cloud top region. Although Gregory's scheme could partly reproduce profiles of the entrainment terms, the reproduction is limited to the shallow convection, and the peak values and qualitative trends are not in agreement with measured profiles (see also Fig. 5).

Because the entrainment term changes the vertical profile of $w_{u}$ as in Eq. (4), the cloud mean updraft velocity equation should reflect the modification of entrainment term. The entrainment term expressed by Eq. (10) is incorporated into Eq. (4) rather than Eq. (3) because the detrainment effect 


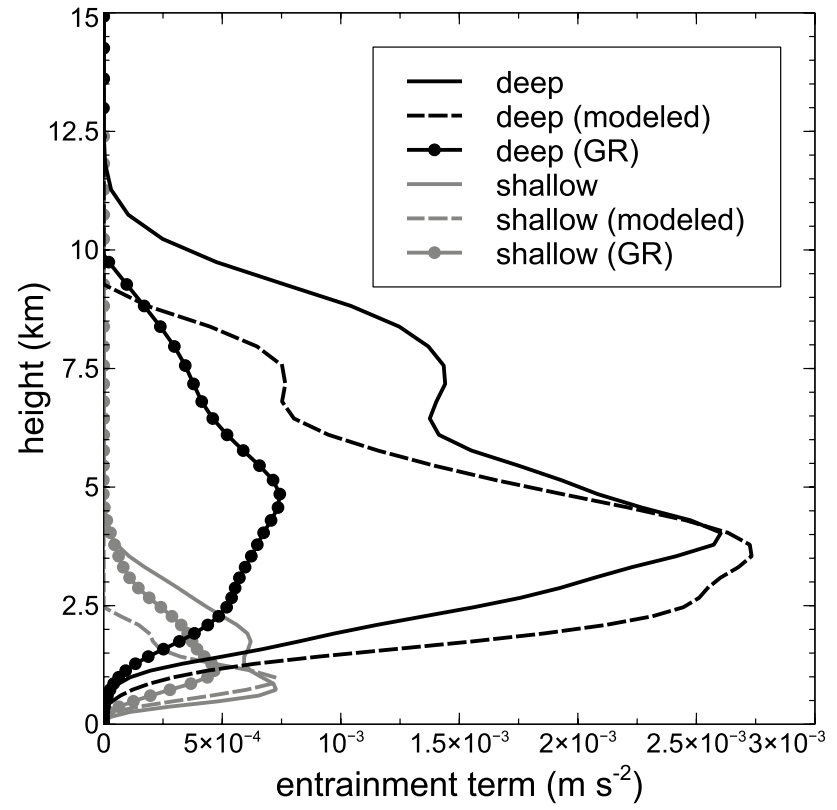

Fig. 5 Comparison of profiles of entrainment term with profiles of modeled entrainment term. The model parameters are set to $C_{1}=0.2$ and $C_{2}=0.2$ in Eq. (10). Profiles obtained from Gregory's scheme (GR) are shown as references $\left(C_{\epsilon}=0.25\right.$ for deep and $C_{\epsilon}=0.5$ for shallow convection)

is now considered in Eq. (10). The modified cloud mean updraft velocity equation can be written as:

$\frac{1}{2} \frac{\partial w_{u}^{2}}{\partial z}=\left(a-C_{1}\right) B_{u}-\left(b-C_{2}\right) \delta_{u} w_{u}^{2}$.

The remaining quantity, i.e., detrainment rate $\delta_{u}$, can be obtained from the detrainment model (which will be described later). Denoting $a_{n}=a-C_{1}$ and $b_{n}=b-C_{2}$, Eq. (11) can be expressed as:

$\frac{1}{2} \frac{\partial w_{u}^{2}}{\partial z}=a_{n} B_{u}-b_{n} \delta_{u} w_{u}^{2}$.

Estimation of the additional parameters of $a_{n}$ and $b_{n}$ was performed using results of CRM experiments as done for $C_{1}$ and $C_{2}$. The estimation revealed that the parameters of $a_{n} \approx 0.5$ and $b_{n} \approx 0.75$ yield good results. Figure 6 shows profiles of the LHS and RHS terms of Eq. (12) using these values for $a_{n}$ and $b_{n}$. The profiles of the modeled RHS term match the profiles of the LHS term for both deep and shallow convection, although there remains deviation for higher altitude regions of deep convection. This indicates that the selected parameters can satisfy the balance of the Eq. (12) for both deep and shallow convection.

The remaining problem is which method is appropriate to model the detrainment rate. Recently, Derbyshire et al. (2011) proposed an adaptive detrainment model for

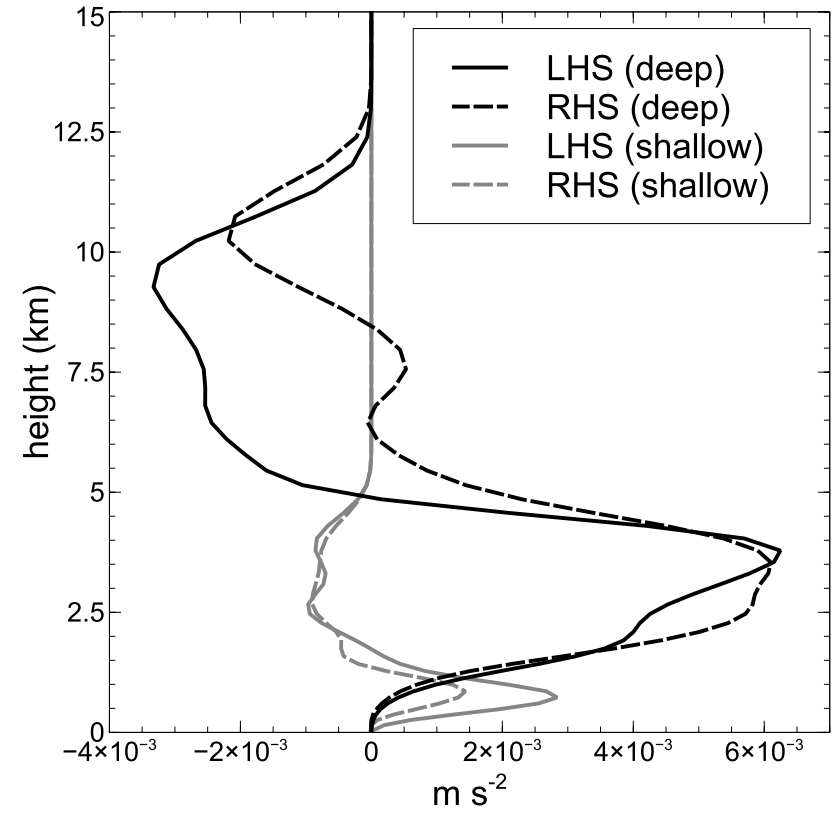

Fig. 6 Vertical profiles of the summed terms in Eq. (12). 'LHS' and 'RHS' refer to the left-hand side and right-hand side summed terms, respectively. The model parameters were chosen as $a_{n}=0.5$ and $b_{n}=0.75$. The profile of $w_{u}$ in Eq. (12) is given by the results from the CRQE experiment

cumulus parameterization. The parameterization uses buoyancy expressed by virtual potential temperature excess to environment $\theta_{v}^{\prime}$ and is given as:

$\delta_{u}=-R_{\text {det }}\left(\frac{\partial \ln \theta_{v}^{\prime}}{\partial z}\right)_{*}, \quad \frac{\partial \ln \theta_{v}^{\prime}}{\partial z}=\left(1-R_{\text {det }}\right)\left(\frac{\partial \ln \theta_{v}^{\prime}}{\partial z}\right)_{*}$

where $R_{\text {det }}=1 / 2$ is the model parameter, and the subscript * indicates the value is obtained before the detrainment is evaluated. The validity of this model for the present study was examined comparing the measured and modeled detrainment (Fig.7). The comparison shows that the parameterization of Derbyshire et al. (2011) approximates the measured detrainment qualitatively well, and so the parameterization can be applied to model the detrainment rate in Eq. (10). It should be noted here that since Eq. (13) parameterizes detrainment rate using in-cloud buoyancy, resulting parameterization expressed in Eq. (10) becomes buoyancy dependent parameterization. 


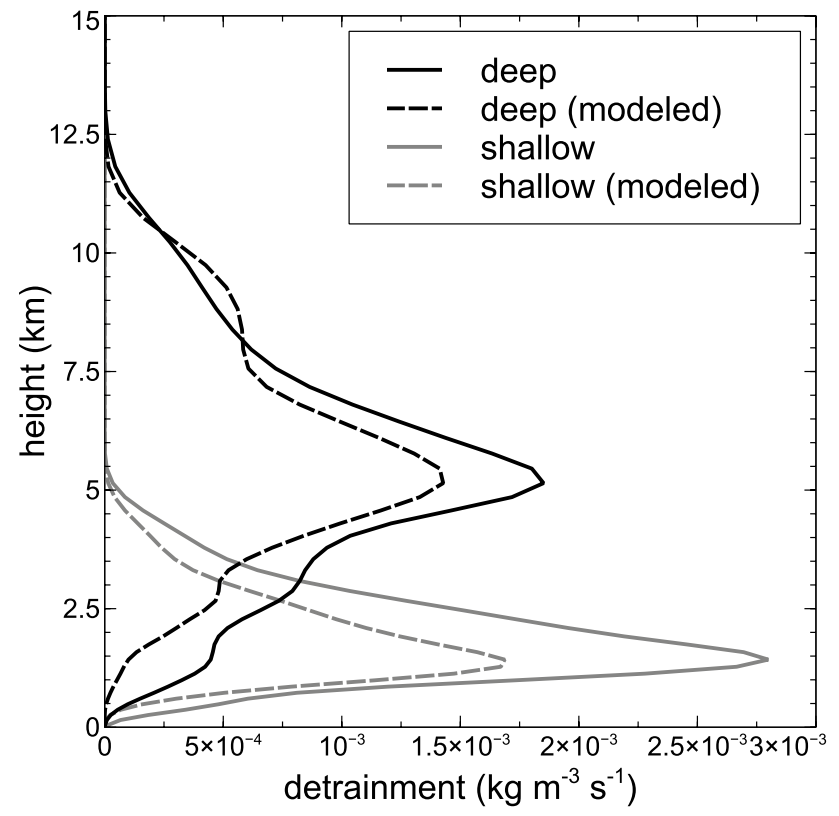

Fig. 7 Comparison of conditionally averaged vertical profiles of measured and modeled detrainment. The profiles of 'modeled' are obtained from Eq. (13)

\section{Spectral cumulus parameterization}

\subsection{Updraft budget equations}

The above formulations of entrainment were applied to the spectral cumulus parameterization. The parameterized entrainment rate was used in the updraft budget equations to compute updraft cloud mass flux and in-cloud quantities. Based on the preceding studies (e.g., Tiedtke 1989; Nordeng 1994; Yoshimura et al. 2015), the updraft budget equations for the $j$-th cloud type, where superscript $j$ denotes the value of $j$-th convective cloud type, are given as:

$\frac{\partial M_{u}^{j}}{\partial z}=E_{u}^{j}-D_{u}^{j}$,

$\frac{\partial M_{u}^{j} s_{u}^{j}}{\partial z}=E_{u}^{j} \bar{s}-D_{u}^{j} s_{u}^{j}+L \bar{\rho} c_{u}^{j}+L_{f} \bar{\rho} f_{u}^{j}$

$\frac{\partial M_{u}^{j} q_{u}^{j}}{\partial z}=E_{u}^{j} \bar{q}-D_{u}^{j} q_{u}^{j}-\bar{\rho} c_{u}^{j}$,

$\frac{\partial M_{u}^{j} l_{u}^{j}}{\partial z}=E_{u}^{j} \bar{l}-D_{u}^{j} l_{u}^{j}+\bar{\rho} c_{u}^{j}-\bar{\rho} G_{p}^{j}$

$\frac{\partial M_{u}^{j} i_{u}^{j}}{\partial z}=E_{u}^{j} \bar{i}-D_{u}^{j} i_{u}^{j}+\bar{\rho} c_{u, i}^{j}+\bar{\rho} f_{u}^{j}-\bar{\rho} G_{p, i}^{j}$, $\frac{\partial M_{u}^{j} \mathbf{v}_{u}^{j}}{\partial z}=E_{u}^{j} \overline{\mathbf{v}}-D_{u}^{j} \mathbf{v}_{u}^{j}+\mathbf{P}_{\mathbf{u}}^{j}$,

where the symbol ${ }^{-}$denotes an environmental value, $M_{u}$ is the updraft cloud mass flux, $s$ is the dry static energy, $q$ is the humidity, $l$ is the total cloud condensate, $i$ is the cloud ice content, $L$ is the effective latent heat, $L_{f}$ is the latent heat of fusion, $c_{u}$ is the cloud condensation rate, $f_{u}$ is the freezing rate, $G_{p}$ is the precipitation generation rate, and $\mathbf{v}$ is the horizontal (zonal and meridional) velocities. Note that $l$ represents total cloud condensate, thus the cloud ice content $i$ is included in the value of $l$, and the cloud water content can be diagnosed by $l-i$. $\mathbf{P}_{\mathbf{u}}$ is the pressure gradient term for convective momentum transport (CMT, see Appendix 6). Numerical evaluation of the budget equations is described in Appendix 1. The deposition rate of cloud ice $c_{u, i}$ is given by:

$c_{u, i}=\eta(\bar{T}) c_{u}, \quad \eta(\bar{T})=\frac{T_{0}-\bar{T}}{T_{0}-T_{i}}$,

where $\eta(\bar{T})$ is the ice fraction $(0 \leq \eta(\bar{T}) \leq 1), T_{0}=273.15 \mathrm{~K}$ is the melting temperature, and $T_{i}=258 \mathrm{~K}$. The generation rate of snow $G_{p, i}$ is expressed as $G_{p, i}=G_{p} i_{u} / l_{u}$. The details of microphysical terms are described in Appendix 8. The updraft entrainment $E_{u}$ and detrainment $D_{u}$ are expressed using cloud mass flux, entrainment rate and detrainment rate as:

$E_{u}=\epsilon_{u} M_{u}, \quad D_{u}=\delta_{u} M_{u}$.

The updraft entrainment rate $\epsilon_{u}$ is given by the relationship obtained from the Eq. (10) as

$\epsilon_{u}=\frac{C_{1} B_{u}-C_{2} \delta_{u} w_{u}^{2}}{w_{u}^{2}}$

The updraft detrainment rate $\delta_{u}$ appearing in Eqs. (21) and (22) is modeled by Eq. (13) as described before.

The above equations are solved for different cloud types, i.e., in-cloud quantities are different for each cloud type. Each cloud type is characterized and initialized by different values of $w_{b}$, i.e., $w_{u}$ at the cloud base in Eq. (12). It should be noted that each cloud type has a possbility to correspond to deep or shallow convection, depending on the atmospheric condition and characterization at the cloud base. In the vertical integration of the budget equation, Eq. (12) is integrated simultaneously, since the value of $w_{u}$ is required to calculate entrainment rate (see Appendix 2 for the discretization). Since $w_{b}$ mainly takes the value ranging from 0.1 to $1.4 \mathrm{~m} \mathrm{~s}^{-1}$, these are set to minimum and maximum values of $w_{b}$. The spectral distribution of $w_{b}$ (as shown in Fig. 1) is considered by using constant interval of $0.1 \mathrm{~m} \mathrm{~s}^{-1}$ and weighting factors (expressed as $\alpha^{j}$ hereafter), which are used to convert each cloud mass flux to the bulk cloud mass flux. 
The weighting factors are determined so that each value can be proportional to the frequency of $w_{b}$ and the summation becomes equal to the total number of cloud types. Here, the total number of cloud types is set to 14 , which is the same as in Chikira and Sugiyama (2010). However, the influence of number of cloud types is unknown and should be examined in future study. The values of $w_{b}$ are prescribed as noted here, and the cloud base mass flux is diagnosed by the convective closure (see Appendix 4 for the convective closure, and see Appendix 5 for the definitions of bulk updraft mean properties, cloud base height and sub-cloud layer).

\subsection{Downdraft budget equations}

Cumulus parameterization generally considers downdraft budget equations to calculate downdraft cloud mass flux and relating quantities. For simplicity, a spectral approach is not taken, and a bulk downdraft cloud mass flux is solved for the convective downdraft, as done in the preceding studies (Chikira and Sugiyama 2010; Yoshimura et al. 2015). The budget equations and calculation procedures are almost identical to those applied in the cumulus parameterization of atmospheric model of European Center for Medium-Range Weather Forecasts (ECMWF 2014). The budget equations for the convective downdraft are expressed similarly to those for convective updraft as:

$\frac{\partial M_{d}}{\partial z}=E_{d}-D_{d}$

$\frac{\partial M_{d} s_{d}}{\partial z}=E_{d} \bar{s}-D_{d} s_{d}-L \bar{\rho} e_{d}$

$\frac{\partial M_{d} q_{d}}{\partial z}=E_{d} \bar{q}-D_{d} q_{d}+\bar{\rho} e_{d}$

$\frac{\partial M_{d} \mathbf{v}_{d}}{\partial z}=E_{d} \overline{\mathbf{v}}-D_{d} \mathbf{v}_{d}+\mathbf{P}_{\mathbf{d}}$

where $M_{d}$ is the downdraft cloud mass flux, $e_{d}$ is the evaporation rate of precipitation in the downdraft, $\mathbf{P}_{\mathbf{d}}$ is the pressure gradient term for CMT. The budget equations for total condensate and cloud ice are given as:

$\frac{\partial M_{d} l_{d}}{\partial z}=E_{d} \bar{l}-D_{d} l_{d}, \quad l_{d}=0$,

$\frac{\partial M_{d} i_{d}}{\partial z}=E_{d} \bar{i}-D_{d} i_{d}, \quad i_{d}=0$,

i.e., their downdraft quantities are neglected and only effect of compensative transport is considered for the environmental values of these quantities in Eqs. (34) and (35) (this assumes entrained quantities evaporate immediately, and the relating terms which have small impacts on downdraft are omitted here for simplicity). The numerical evaluation of these equations is described in Appendix 3. The downdraft is initiated from the level of free sinking (LFS), and the downdraft mass flux at the height of the LFS is given as $M_{d}=-\eta_{d} M_{b}$, where $\eta_{d}=0.3$ and $M_{b}=\sum_{j} \alpha^{j} M_{b}^{j}$ is the bulk cloud base mass flux. The height of the LFS is located below the minimum saturated moist static energy, and defined as the maximum height where an equal (50\%) mixture of cloudy air and environmental air has negative buoyancy with respect to the environmental air. The downdraft entrainment and detrainment include organized and turbulent components given as:

$E_{d}=\left(\epsilon_{d}^{o r g}+\epsilon_{d}^{t r b}\right) M_{d}, \quad D_{d}=\left(\delta_{d}^{o r g}+\delta_{d}^{t r b}\right) M_{d}$.

The turbulent entrainment and detrainment rates in downdraft are given as (e.g., Tiedtke 1989):

$\epsilon_{d}^{t r b}=\delta_{d}^{t r b}=2 \times 10^{-4} \mathrm{~m}^{-1}$.

The organized entrainment rate in the downdraft is based on Nordeng (1994) and is given as:

$\epsilon_{d}^{\text {org }}=\frac{-B_{d}}{w_{d, L F S}^{2}-\int_{z}^{L F S} B_{d} d z}, \quad B_{d}=g \frac{T_{v, d}-\bar{T}_{v}}{\bar{T}_{v}}$,

where $w_{d, L F S}=1 \mathrm{~m} \mathrm{~s}^{-1}$ is the downdraft velocity at the LFS and $T_{v, d}$ is the downdraft virtual temperature. The organized downdraft detrainment rate is indirectly determined from decrease of downdraft cloud mass flux. The organized downdraft detrainment occurs when the downdraft is thermodynamically positive buoyant or reaches below the cloud base. When the downdraft is positive buoyant, downdraft cloud mass flux detrains over one model layer, i.e., turbulent detrainment rate is neglected and the organized detrainment rate is set to $\delta_{d}^{\text {org }}=1 / \Delta z$ where $\Delta z$ is the layer thickness. Below the cloud base, downdraft cloud mass flux decreases linearly with respect to the height, and this decrease is used to account for the detrainment. In this case, turbulent detrainment rate is also neglected, and the organized detrainment rate is given as $\delta_{d}^{\text {org }}=1 / z$.

\subsection{Tendency to environment}

The tendencies of convective updraft and downdraft to the environment are given as (e.g., Tiedtke 1989; Nordeng 1994; Yoshimura et al. 2015):

$\bar{\rho} \frac{\partial \bar{s}}{\partial t}=\sum_{j} \alpha^{j}\left[-\frac{\partial}{\partial z}\left(M_{u}^{j} s_{u}^{j}-M_{u}^{j} \bar{s}\right)+L \bar{\rho} c_{u}^{j}+L_{f} \bar{\rho} f_{u}^{j}\right]-\frac{\partial}{\partial z}\left(M_{d} s_{d}-M_{d} \bar{s}\right)$

$-L \bar{\rho} e_{d}-L \bar{\rho} \tilde{e_{p}}-L_{f} M_{m e l t}$, 


$$
\begin{aligned}
\bar{\rho} \frac{\partial \bar{q}}{\partial t}= & \sum_{j} \alpha^{j}\left[-\frac{\partial}{\partial z}\left(M_{u}^{j} q_{u}^{j}-M_{u}^{j} \bar{q}\right)-\bar{\rho} c_{u}^{j}\right] \\
& -\frac{\partial}{\partial z}\left(M_{d} q_{d}-M_{d} \bar{q}\right)+\bar{\rho} e_{d}+\bar{\rho} \tilde{e_{p}},
\end{aligned}
$$

$$
\bar{\rho} \frac{\partial \bar{l}}{\partial t}=\sum_{j} \alpha^{j}\left[-\frac{\partial}{\partial z}\left(M_{u}^{j} l_{u}^{j}-M_{u}^{j} \bar{l}\right)+\bar{\rho} c_{u}^{j}-\bar{\rho} G_{p}^{j}\right]-\frac{\partial}{\partial z}\left(M_{d} l_{d}-M_{d} \bar{l}\right),
$$

$$
\begin{aligned}
\bar{\rho} \frac{\partial \bar{i}}{\partial t}= & \sum_{j} \alpha^{j}\left[-\frac{\partial}{\partial z}\left(M_{u}^{j} i_{u}^{j}-M_{u}^{j} \bar{i}\right)+\bar{\rho} c_{u, i}^{j}+\bar{\rho} f_{u}^{j}-\bar{\rho} G_{p, i}^{j}\right] \\
& -\frac{\partial}{\partial z}\left(M_{d} i_{d}-M_{d} \bar{i}\right),
\end{aligned}
$$

$$
\bar{\rho} \frac{\partial \overline{\mathbf{v}}}{\partial t}=\sum_{j} \alpha^{j}\left[-\frac{\partial}{\partial z}\left(M_{u}^{j} \mathbf{v}_{\mathbf{u}}^{j}-M_{u}^{j} \overline{\mathbf{v}}\right)+\mathbf{P}_{u}^{j}\right]-\frac{\partial}{\partial z}\left(M_{d} \mathbf{v}_{d}-M_{d} \overline{\mathbf{v}}\right)+\mathbf{P}_{d},
$$

where $M_{\text {melt }}$ is the melting rate of snow, $\tilde{e_{p}}$ is the evaporation (sublimation) rate of precipitation which is given to the environment. The first and second terms on the right-hand side of the equations represent compensative transport due to updraft and downdraft, and so the transports of prognostic quantities must be solved in the cumulus parameterization (see Appendix 7).

The precipitation fluxes at the ground surface are obtained by integrating a generation rate of precipitation with evaporation (sublimation) rate as:

$$
\begin{aligned}
& P=\int_{z=0}^{z_{t}} \bar{\rho}\left[\sum_{j} \alpha^{j} G_{p}^{j}-e_{d}-\tilde{e}_{p}\right] d z, \\
& P_{\text {snow }}=\int_{z=0}^{z_{t}} \bar{\rho}\left[\sum_{j} \alpha^{j} G_{p, i}^{j}+F_{\text {ice }}\left(-e_{d}-\tilde{e}_{p}\right)\right] d z,
\end{aligned}
$$

where $P$ is the total precipitation flux, $P_{\text {snow }}$ is the snow flux, $F_{\text {ice }}=P_{\text {snow }} / P$ is the ice fraction for precipitation, and the rain flux is defined as $P_{\text {rain }}=P-P_{\text {snow }}$. Integrating the right-hand side of Eqs. (37) and (38) from the cloud top to a certain height $z$ gives precipitation fluxes at the height of $z$, and these fluxes are used in the downdraft calculation to compute the evaporation of precipitation within downdraft.

\section{SCM experiment}

\subsection{Model and experimental setup}

SCM experiments are useful to understand essential properties of developed cumulus parameterization since they can reduce influences of simulated large-scale atmospheric motion and uncertainty of other physical parameterizations. The experimental setup of the present SCM experiment follows Zhang and McFarlane (1995). The constant radiative cooling of $2 \times 10^{-5} \mathrm{~K} \mathrm{~s}^{-1}$ was given and set to linearly decrease above $100 \mathrm{mb}$ level. Sensible and latent heat fluxes were imposed at the surface using non-dimensional drag coefficients which values given as $2 \times 10^{-3}$. The vertical coordinate was discretized with an interval of $25 \mathrm{mb}$, and 40 layers were used. Dry adiabatic adjustment was activated when the atmospheric condition becomes statistically unstable, and large-scale condensation was activated when saturation of water vapor occurs. The initial profile of atmosphere was created from the data of Intensive Flux Array averaged fields of the Tropical Ocean Global Atmosphere Coupled Ocean-Atmosphere Response Experiment (Ciesielski et al. 2003) by taking the average of profiles with rainfall greater than 20 $\mathrm{mm}$ day $^{-1}$. Time integration was performed for 30 days, and mean vertical profiles of convective clouds were analyzed using the results of the last 15 days.

To clarify the difference between the developed parameterization (new scheme hereafter) and existing parameterization, Gregory (2001) (GR scheme hereafter) was used as the existing parameterization for comparison. Following the implementation of Chikira and Sugiyama (2010), the GR scheme uses Eq. (3) for cloud mean updraft velocity equation and Eq. (8) for updraft entrainment rate. The values of model parameters in the equations also follow Chikira and Sugiyama (2010), i.e., $a=0.15$ and $C_{\epsilon}=0.6$. A constant interval of $0.1 \mathrm{~m} \mathrm{~s}^{-1}$ is set to the distribution of $w_{b}$, and the total number of cloud types is set to 14 for the GR scheme.

\subsection{Results}

Figure 8 compares the time evolution of convective available potential energy (CAPE) simulated with the two schemes. It is apparent that the value reaches equilibrium after 5 days although with significant fluctuations. Further, the new scheme simulated larger CAPE than the GR scheme, and thus much deeper clouds are more significant than the GR scheme. Indeed, the average convective rain rate of the new scheme was $12.4 \mathrm{~mm} \mathrm{day}^{-1}$, compared to $8.7 \mathrm{~mm} \mathrm{day}^{-1}$ of the GR scheme. Figure 9 compares averaged vertical profiles of convective heating (cooling) and moistening (drying) rates. The simulated profiles are qualitatively similar to those presented in Zhang and McFarlane (1995) as convective cooling and drying are dominant near the $1000 \mathrm{mb}$ level. Above the level, the new scheme simulated larger convective heating and drying rates up to $400 \mathrm{mb}$ level. This indicates that deeper convective clouds are more significant in the new scheme than that in the GR scheme. 
Fig. 8 Comparison of time evolution of convective available potential energy (CAPE) over 30 days for the GR and new schemes

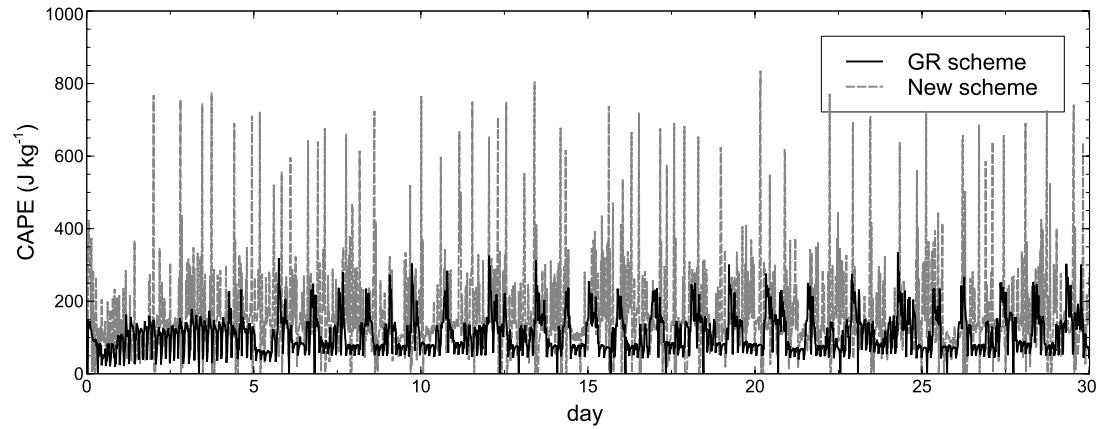

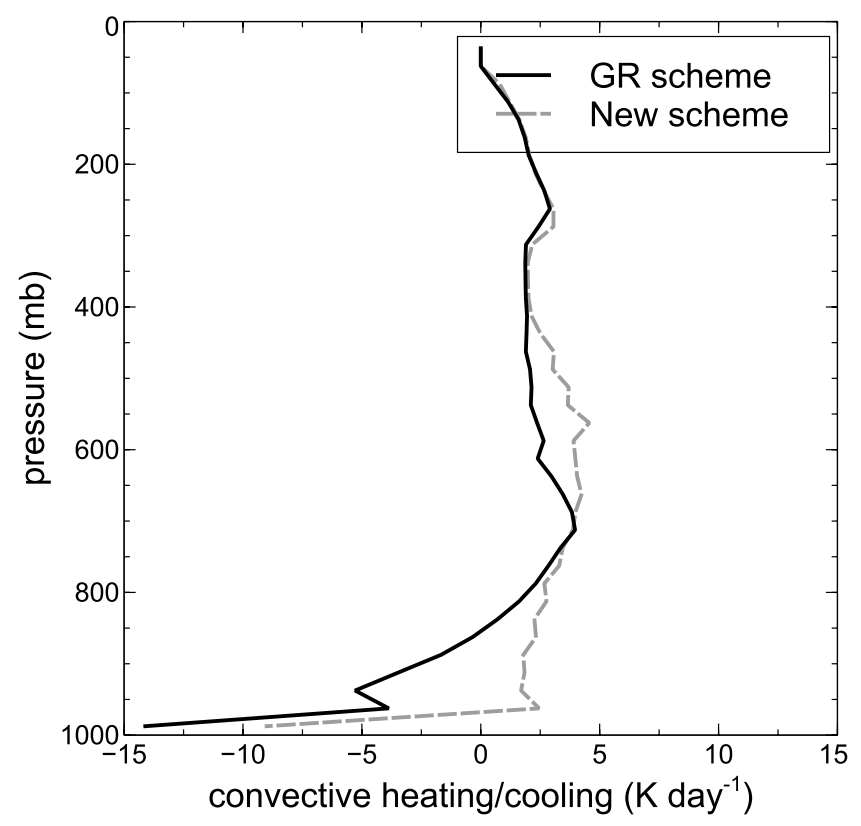

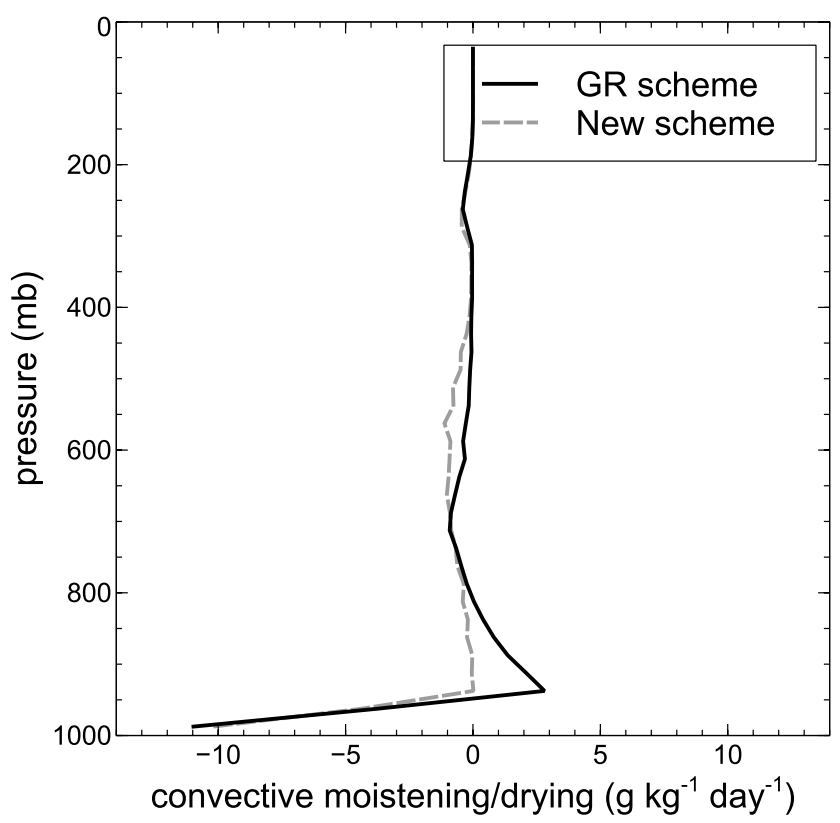

Fig. 9 Comparison of time averaged vertical profiles of convective heating (cooling) and moistening (drying) rates

Time averaged vertical profiles of simulated cloud mass flux for each convective cloud type are compared in Fig. 10. In both schemes, the vertical profiles of each cloud type have a certain spread, but their detailed profiles are different. As the value of $w_{b}$ increases, the GR scheme produces large cloud mass flux above the melting level. In contrast, cloud mass flux simulated with new scheme increases only in the lower altitude. Because shallow convection shows large cloud mass flux and updraft at low altitudes, these trends mean that the GR and new schemes simulate shallow convection with small and large values of $w_{b}$, respectively. The trends of new scheme are consistent with the results of CRM experiment since shallow convection is more dominant for larger value of $w_{b}$.

The time averaged vertical profiles of entrainment and detrainment are compared in Fig. 11. Both entrainment and detrainment profiles show that the GR scheme simulated larger entrainment and detrainment than the new scheme for most altitudes, except near the lowest level. The profiles mean that lateral mixing between clouds and the environmental air in the GR scheme is more active than that in the new scheme. Considering this trend, the trends of CAPE, and the profiles of heating and drying rates (less heating and moistening lower atmosphere), the GR scheme is considered to simulate shallower and more diluted convective clouds than the new scheme. The GR scheme tends to simulate entrainment as long as in-cloud buoyancy remains, and so this feature results in larger entrainment. In the both cases, entrainment remains even near the $200 \mathrm{mb}$ level (approximately $11 \mathrm{~km}$ height) which is much higher than that simulated by CRM. This may be derived from the formulation of Gregory's parameterization for entrainment rate that tends to simulated large entrainment rate near the cloud top. This is because near the cloud top, the updraft velocity is small, and too large value of entrainment rate is likely to appear by dividing the in-cloud buoyancy with the small updraft 
(a) GR scheme

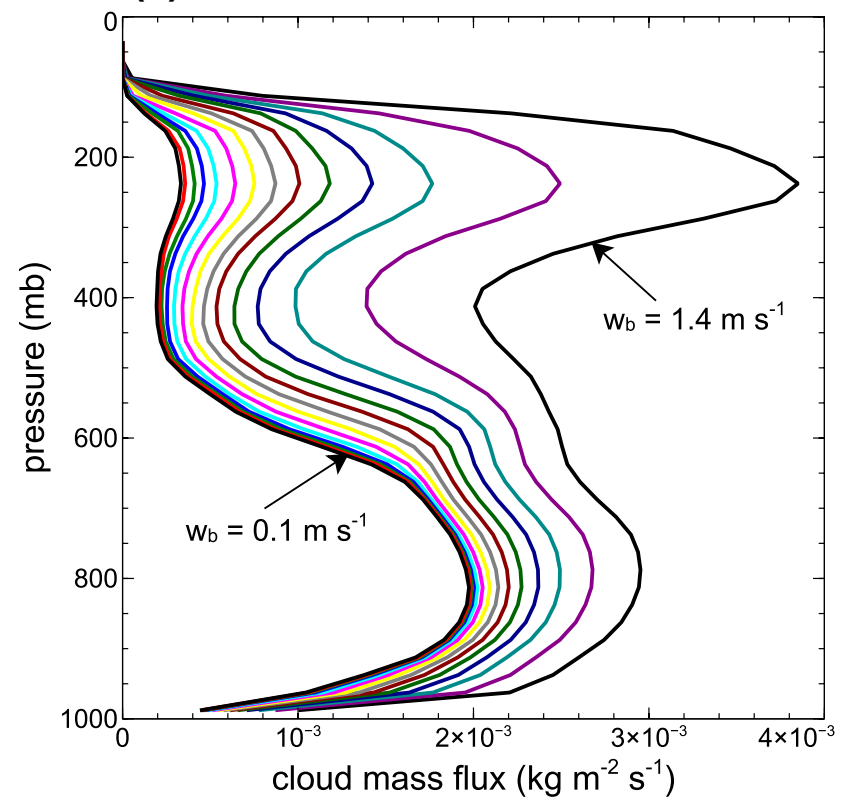

(b) New scheme

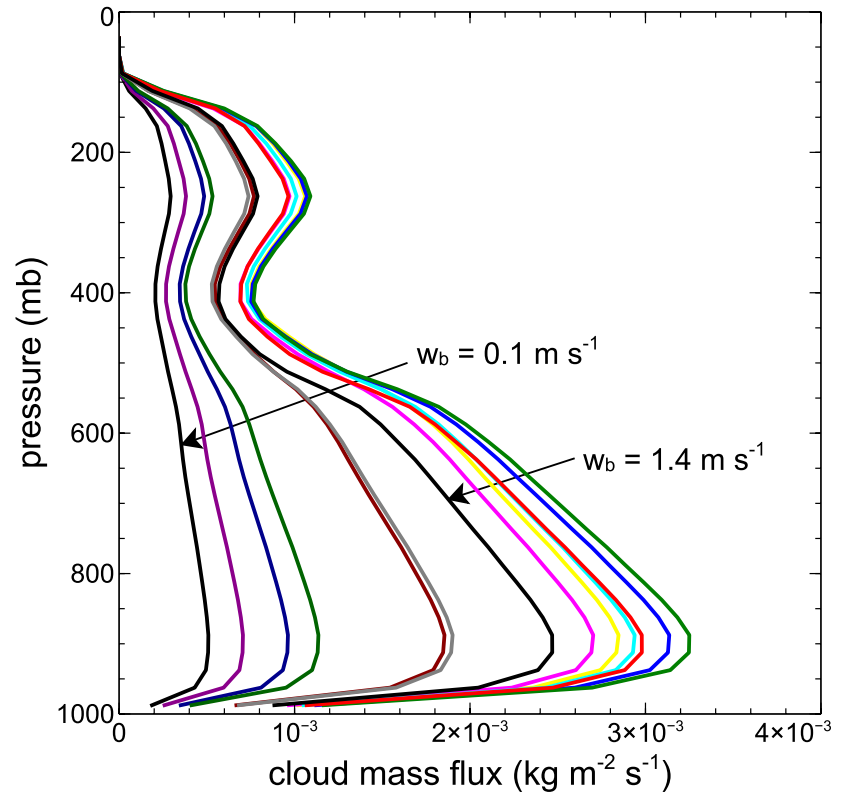

Fig. 10 Comparison of time averaged vertical profiles of updraft cloud mass flux for each cloud type. Different colors correspond to each cloud type. Corresponding cloud base updraft velocities $w_{b}$ are indicated for the profiles of $w_{b}=0.1$ and $1.4 \mathrm{~m} \mathrm{~s}^{-1}$
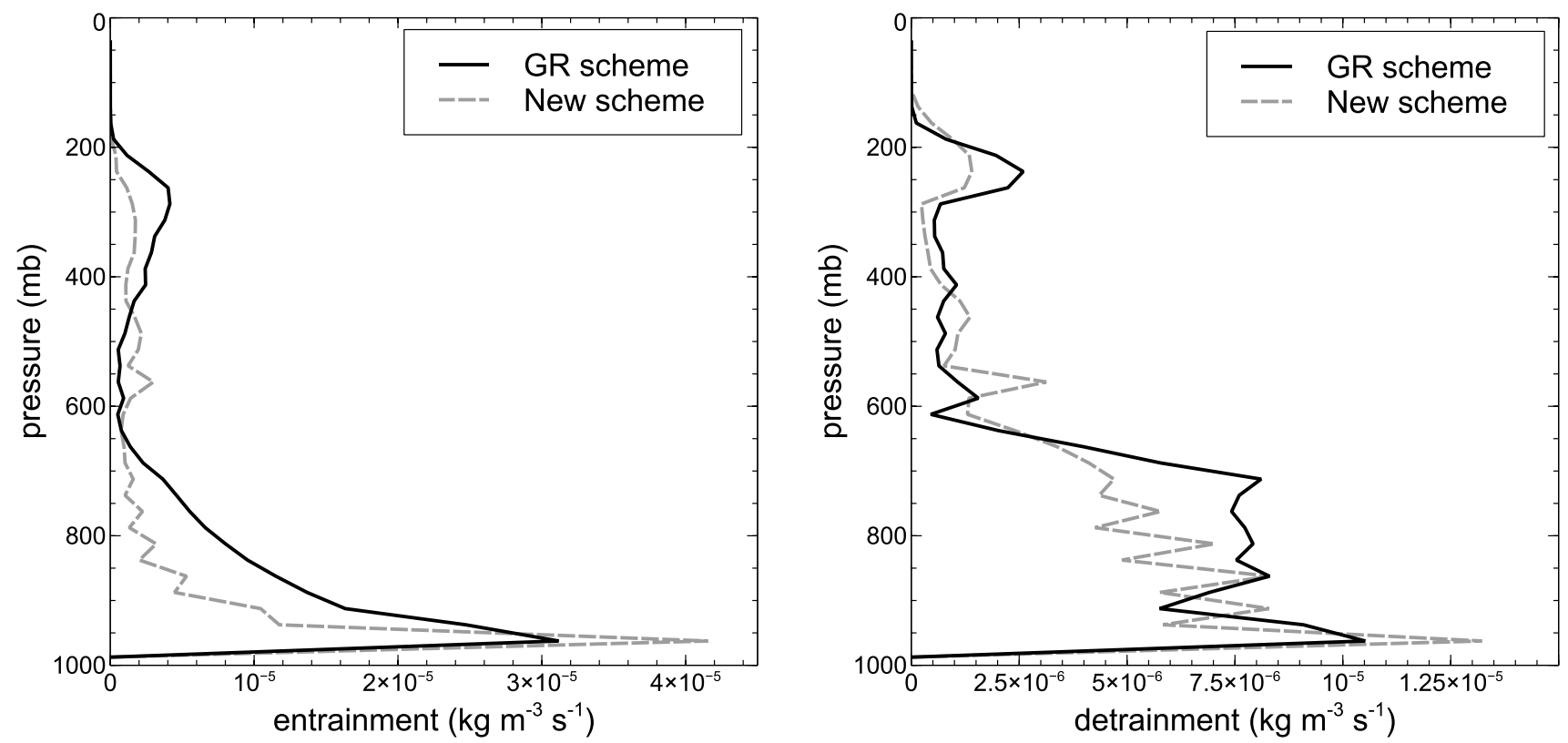

Fig. 11 Comparison of time averaged vertical profiles of entrainment and detrainment

velocity, even though cloud top entrainment appears to be large as presented in Zhang et al. (2016). Similar trends are seen in Fig. 7 of Chikira and Sugiyama (2010) and the solution should be discussed in the future study. Section 6 below uses AMIP experiments to examine the impact of the different features of each scheme on atmospheric circulation.

\section{AMIP experiment}

\subsection{Model and experimental setup}

An atmospheric general circulation model (AGCM), which is a grid model and consists of a composite grid system 
(a) GR scheme
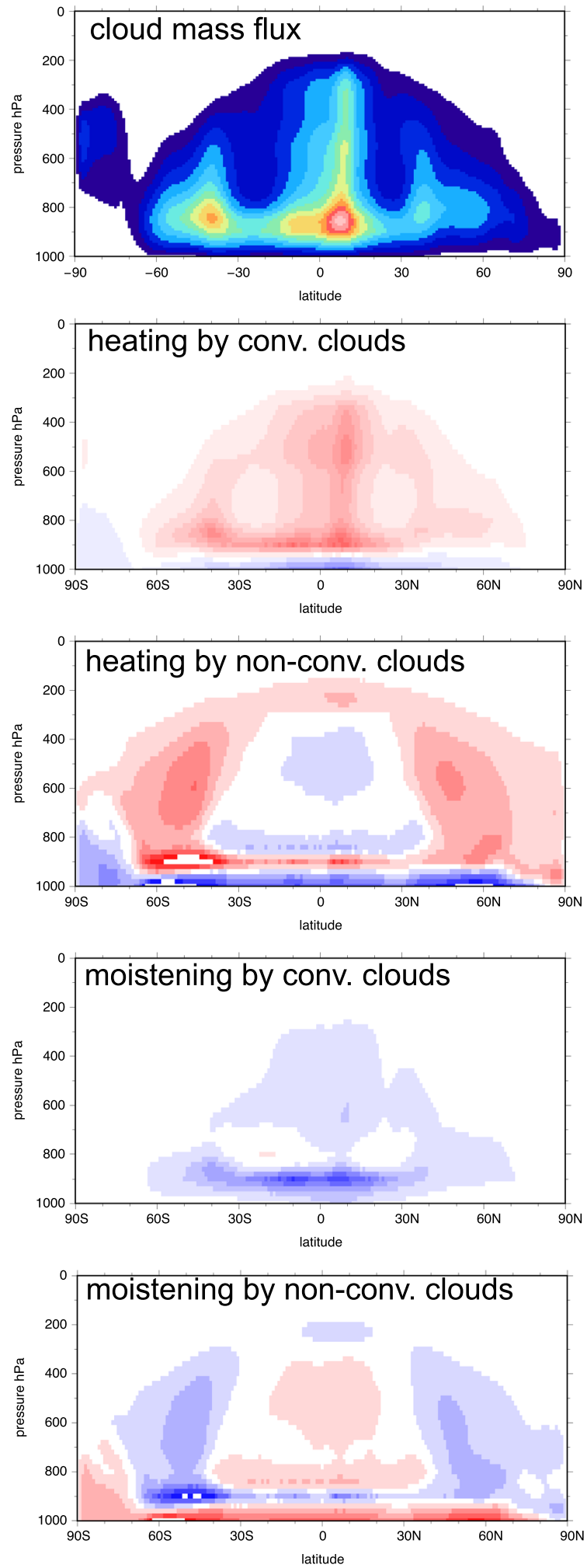

(b) New scheme
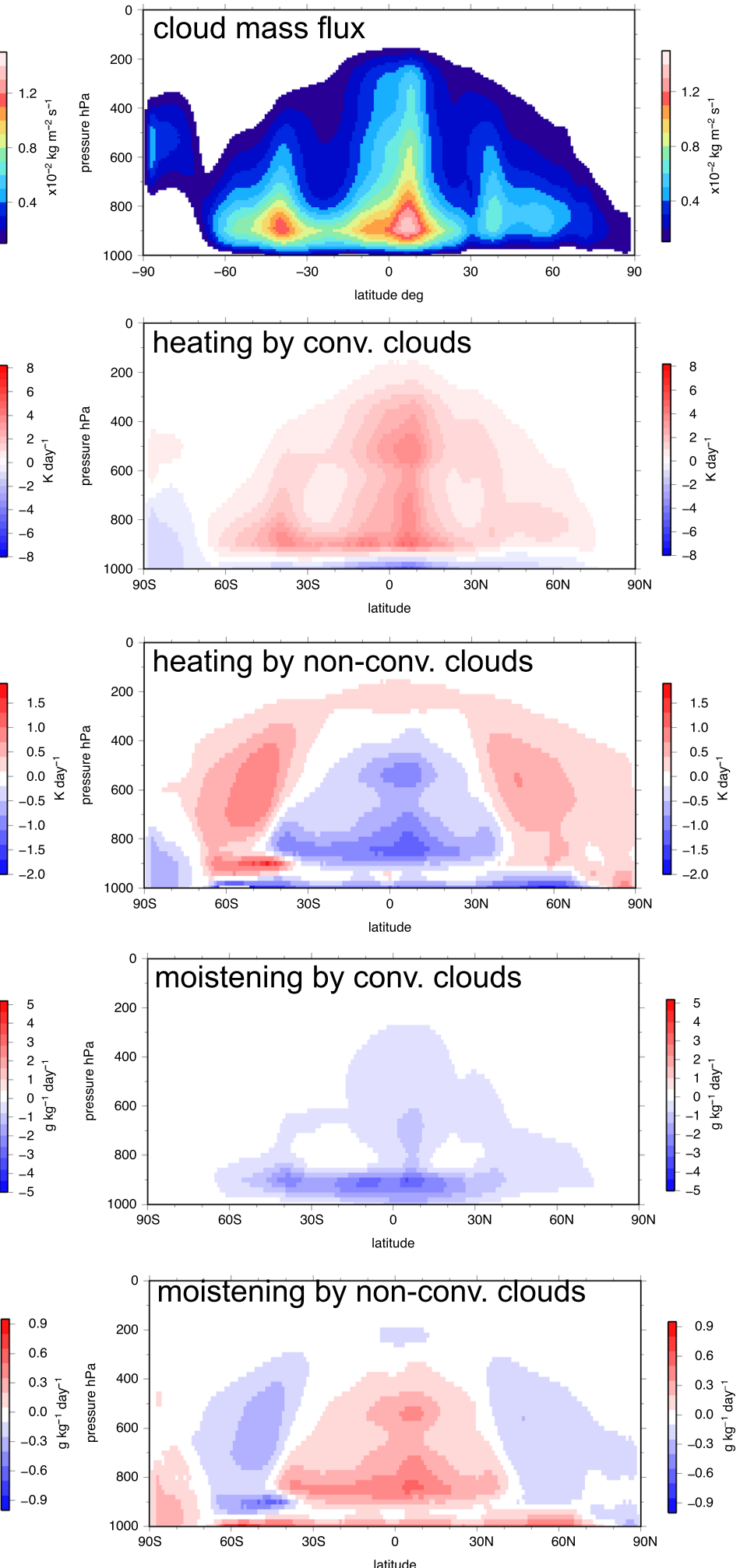

Fig. 12 Zonal mean and annual mean vertical profiles of cloud mass flux, heating and moistening rates by convective and non-convective clouds. Negative values in heating and moistening rates indicate cooling rate and drying rate, respectively 
(a) GR scheme
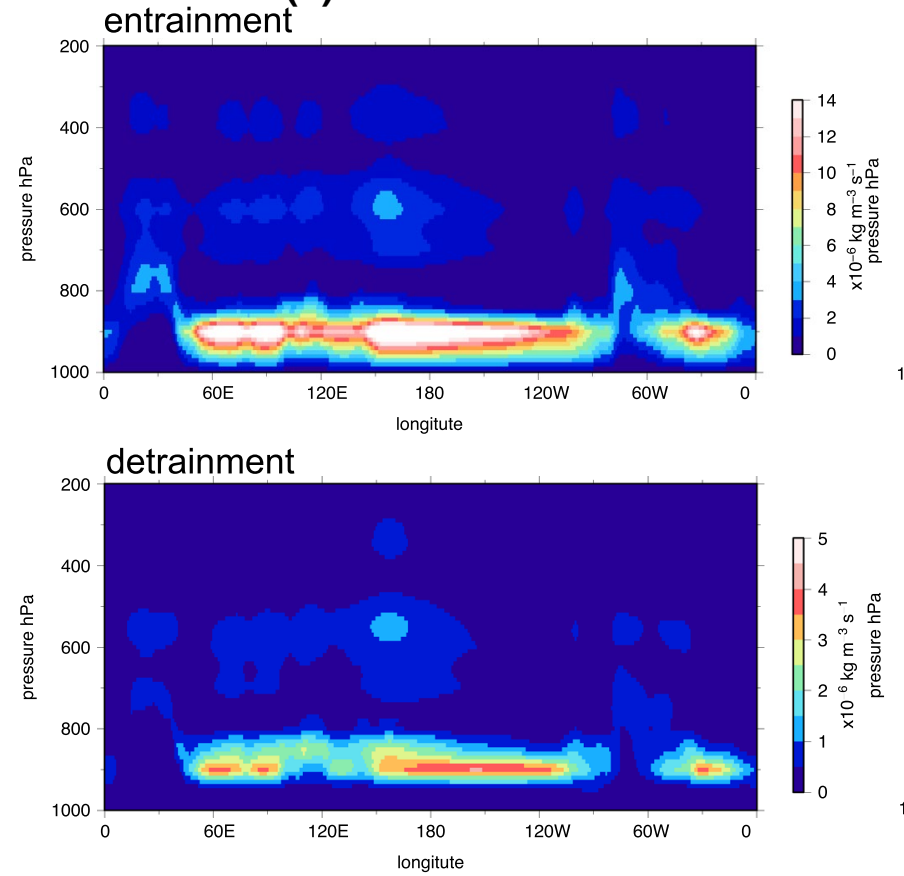

(b) New scheme

entrainment

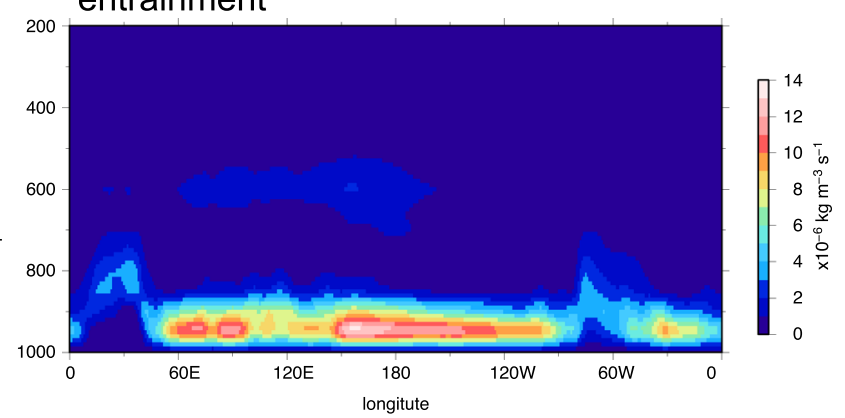

detrainment

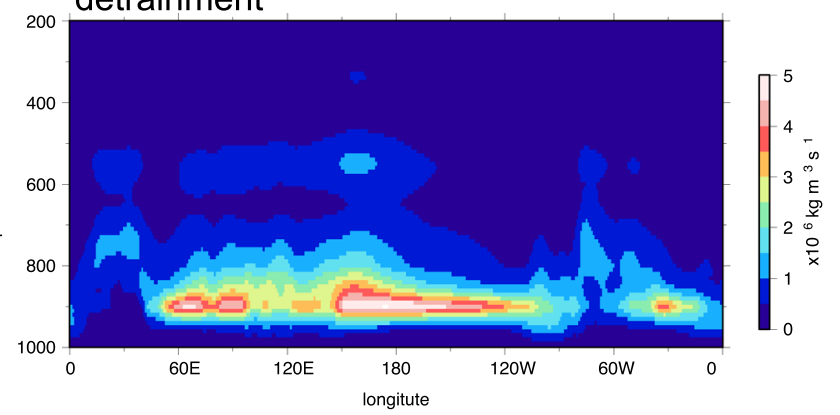

Fig. 13 Meridional mean (averaged between $15^{\circ} \mathrm{S}$ and $15^{\circ} \mathrm{N}$ ) and annual mean vertical profiles of entrainment and detrainment

(a) GR scheme
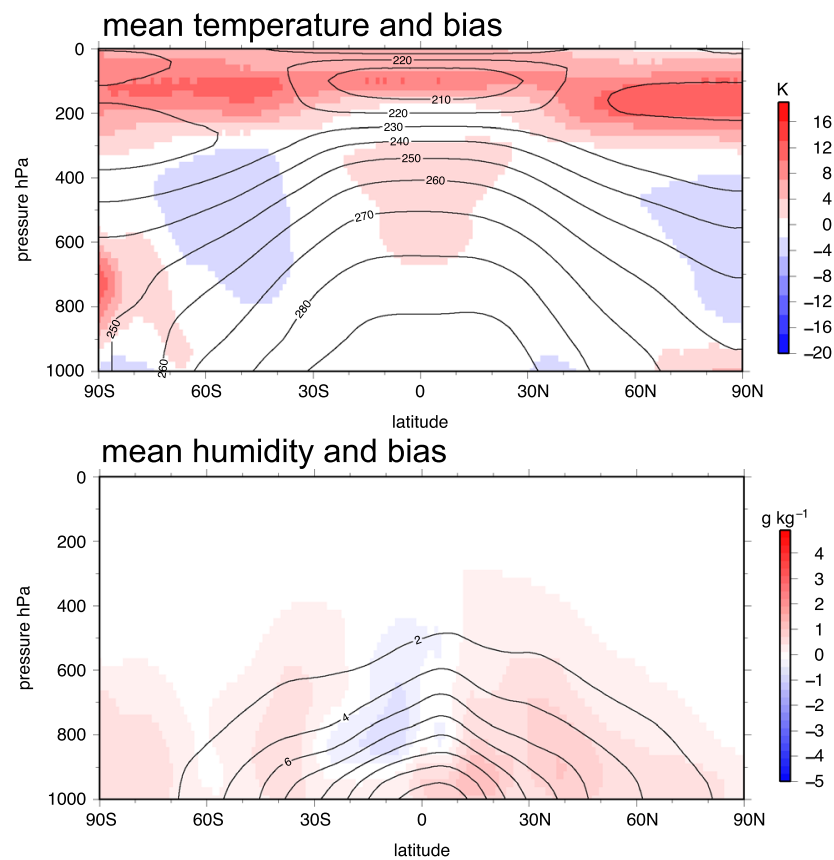

(b) New scheme

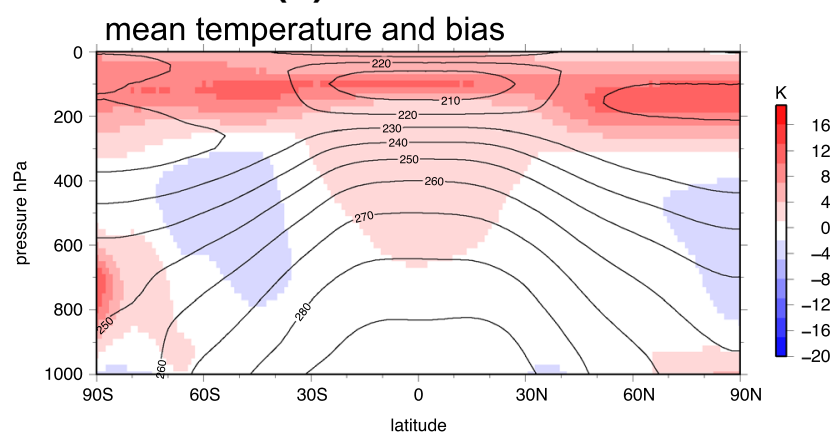

mean humidity and bias

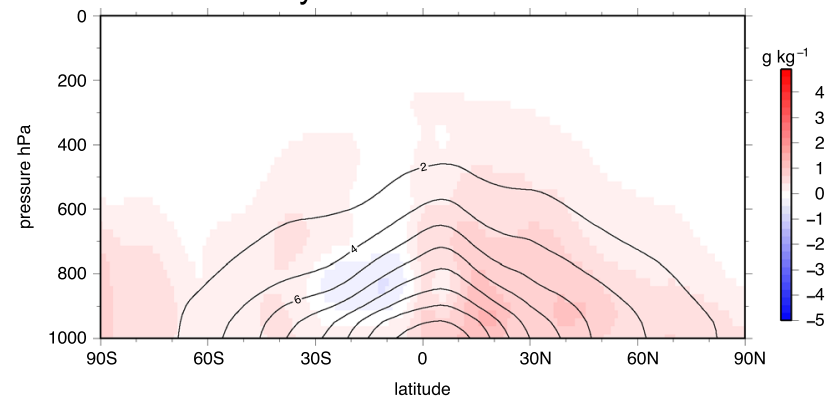

Fig. 14 Zonal mean and annual mean vertical profiles of temperature and humidity biases from ERA-interim using 7-year model results. Contour lines and shade indicate zonal and annually averaged profiles and biases from ERA-interim, respectively 
(Baba et al. 2010) was used for the AMIP experiment. The land surface was parameterized based on the revised Hydrology, tiled ECMWF Scheme for Surface Exchanges over Land (H-TESSEL; ECMWF 2014) including snow process (Dutra et al. 2010). The sea ice temperature was solved by a slab model. The roughness length over ocean was parameterized by Miller et al. (1992). The microphysics of non-convective clouds were based on Lohmann and Roeckner (1996), and partial condensation was computed

(a) GR scheme annual mean precipitation

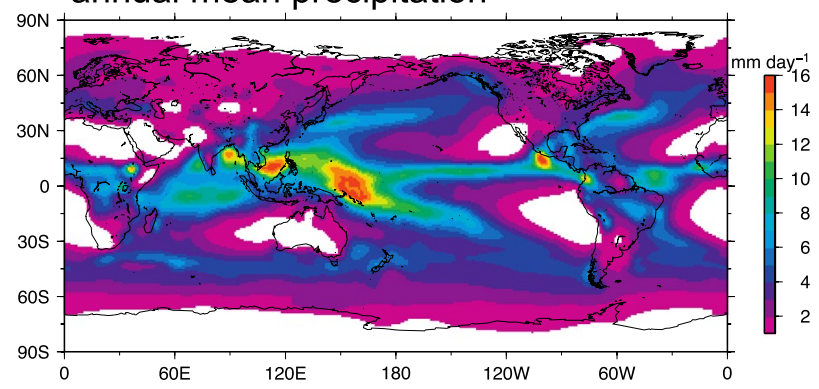

model - CMAP

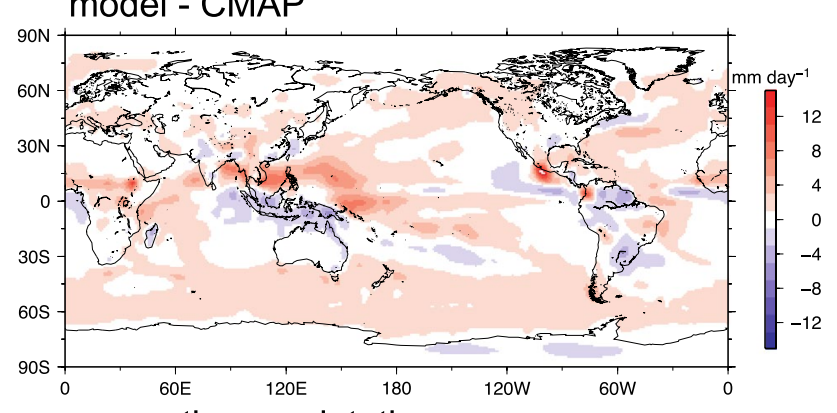
convective preciptation
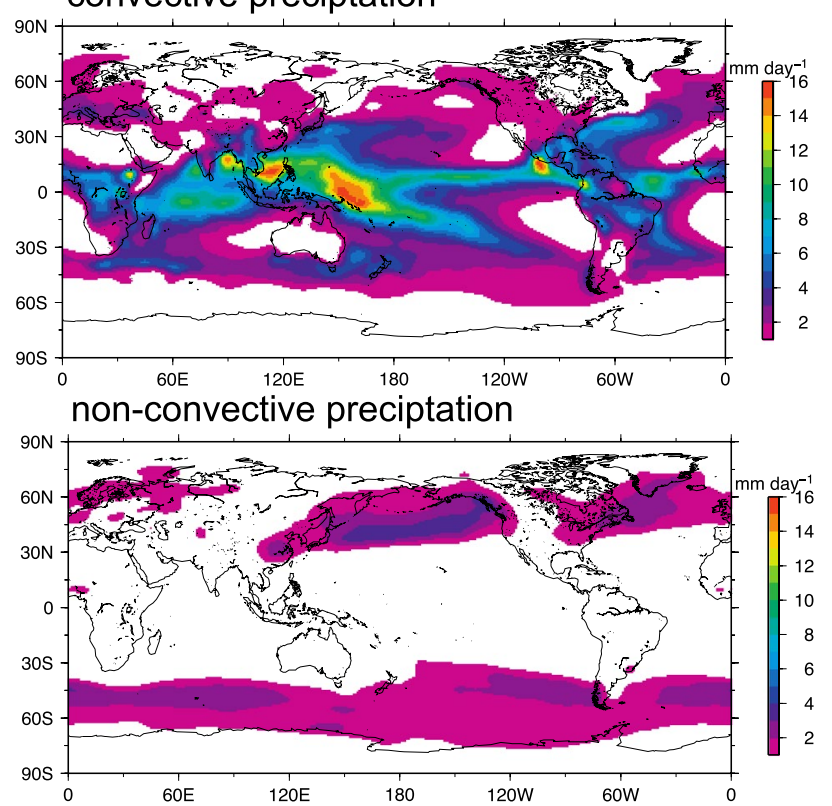

by the method of Kuwano-Yoshida et al. (2010). The orographic and non-orographic gravity waves were parameterized by McFarlane (1987) and Scinocca (2003), respectively. All other parameterizations were same as those used in Baba (2015).

The horizontal resolution of $2.5^{\circ}$ and non-uniformly spaced vertical 51 layers (up to $80 \mathrm{~km}$ height) were used. The first model layer thickness is $100 \mathrm{~m}$ near the model bottom and $2400 \mathrm{~m}$ near $20 \mathrm{~km}$ height. The layer thickness

\section{(b) New scheme}

annual mean precipitation
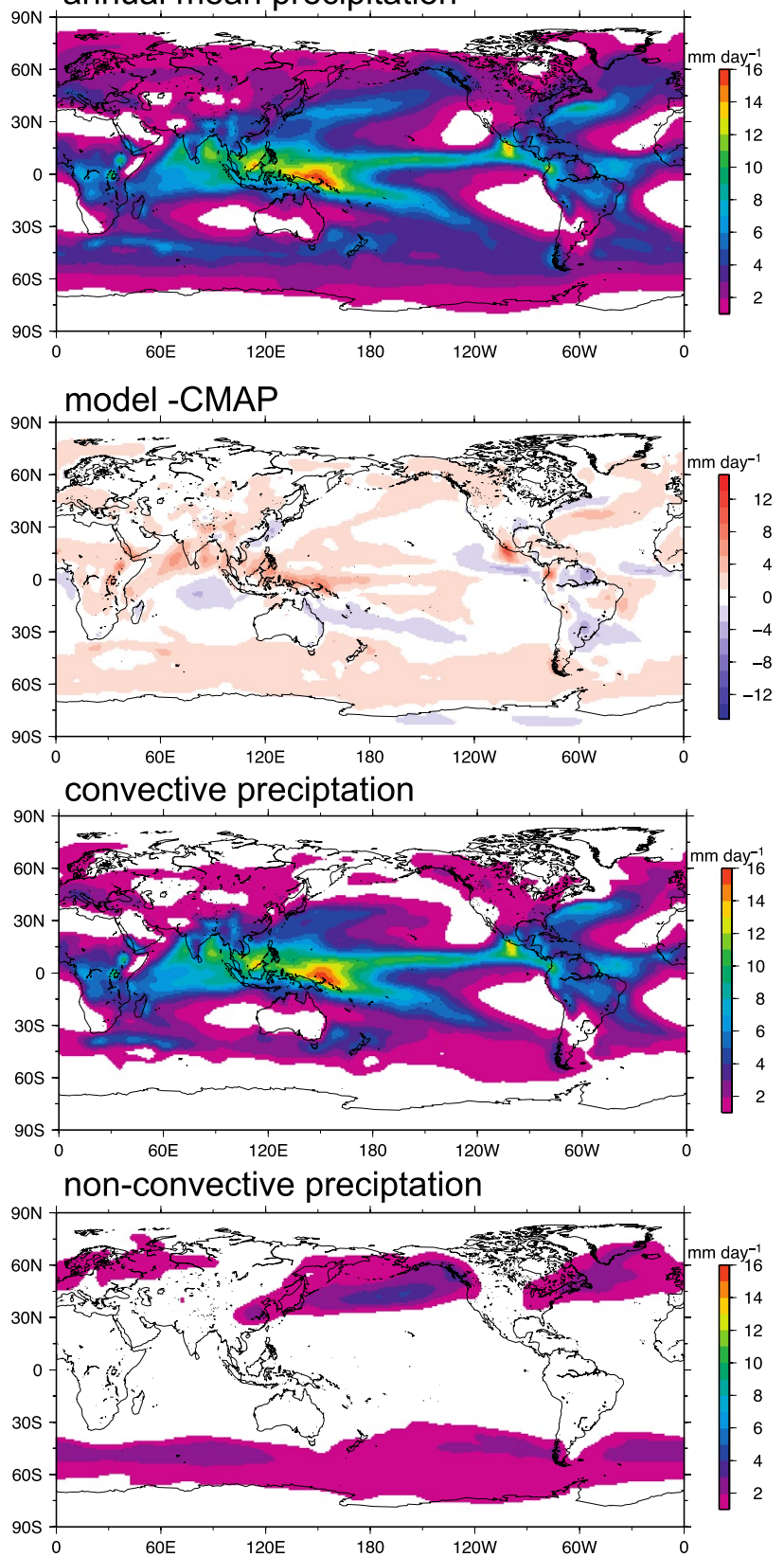

Fig. 15 Comparison of annual mean precipitation, biases from CMAP precipitation data, convective and non-convective precipitation using 7-year model results 
above this level was set to a constant $2400 \mathrm{~m}$. A time step of 26 min was used for the time integration. The experimental setup follows the original AMIP experiment. The sea surface temperature and sea ice concentration were given by reanalysis data (Rayner et al. 2003). Time integration was performed for 7 years from 1 January 1979 to 31 December 1985 , and the daily data were analyzed.

\section{(a) GR scheme}
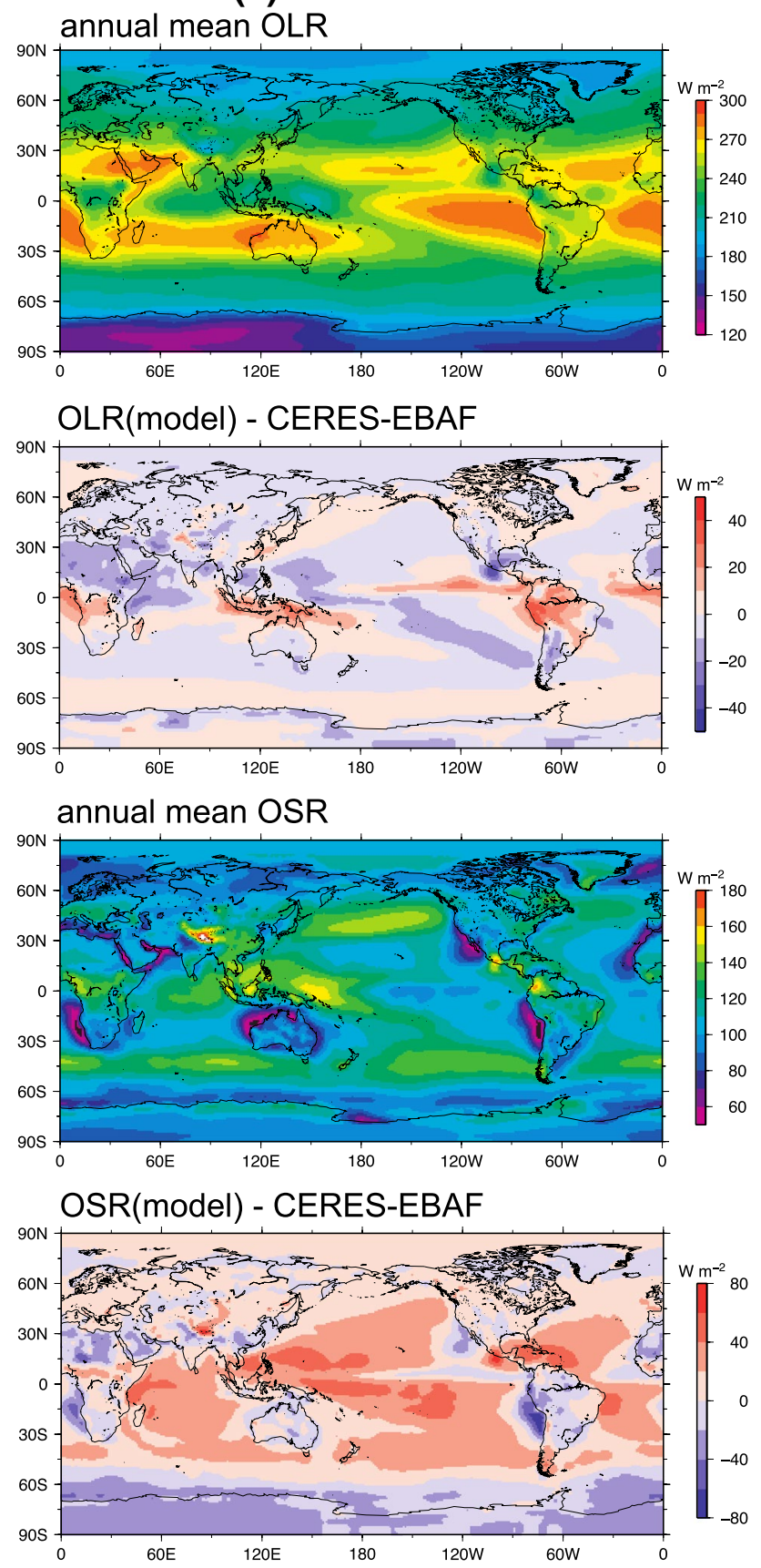

\subsection{Mean state}

Convective and non-convective cloud structures were analyzed by zonal mean vertical profiles of cloud mass flux, heating rate and moistening rate (Fig. 12). The GR scheme simulated weaker cloud mass flux, lower heating and drying rates from convective clouds in the higher altitude, meaning that the convection simulated by the GR scheme is weaker
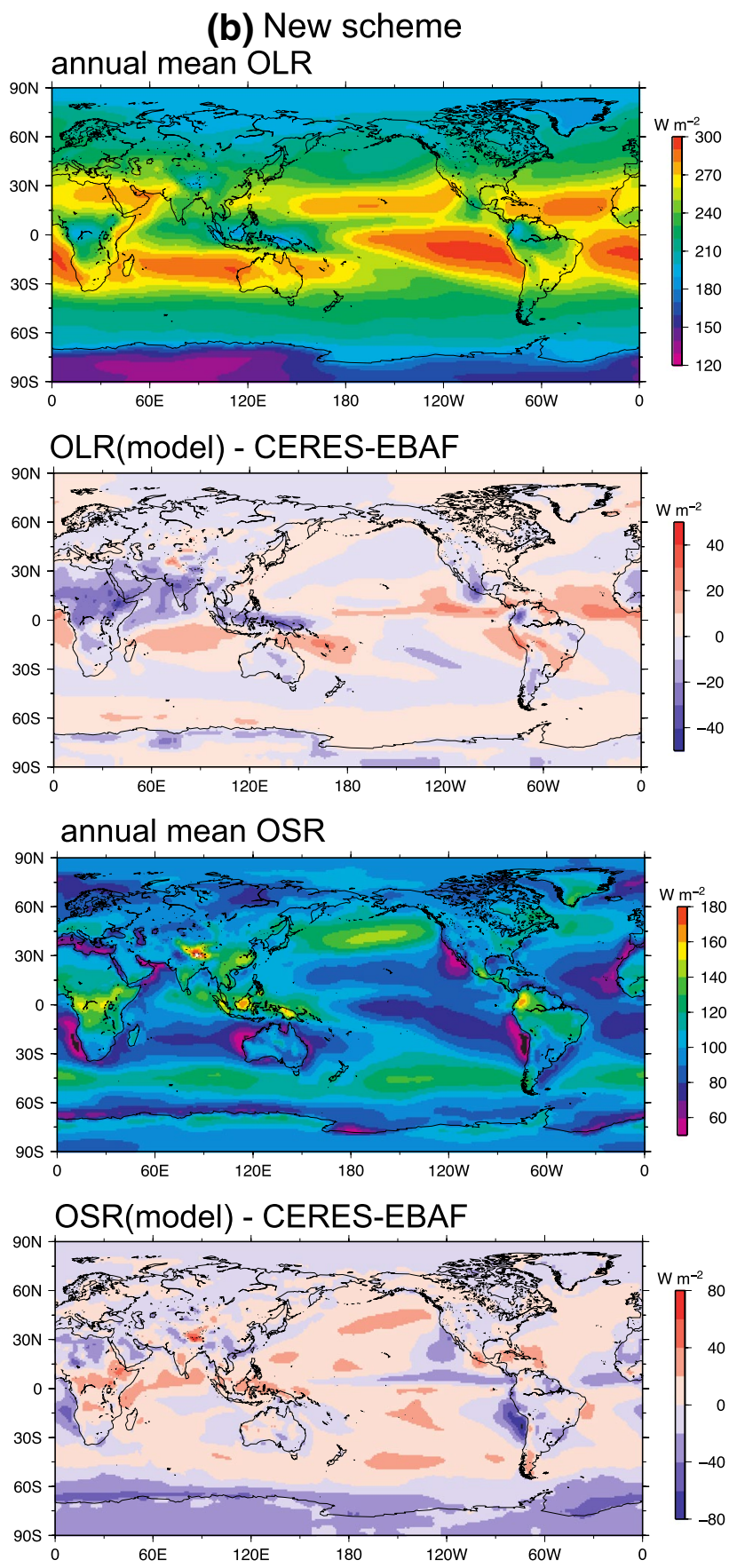

Fig. 16 Comparison of annual mean outgoing longwave radiation (OLR), outgoing shortwave radiation (OSR) and their biases from CERESEBAF satellite data using 7-year model results 
than that simulated by the new scheme. The trends are consistent with the results of SCM experiment, which showed that the GR scheme tended to simulate shallower diluted convection. Responding to the weaker convective updraft, cooling and moistening from non-convective clouds (evaporation of cloud condensate and precipitation) in the upper equatorial region are less significant in the GR scheme due to the weaker vertical circulation, while heating and drying from non-convective clouds (formation of cloud condensate) in the lower equatorial region (height between 1000 and 800 $\mathrm{hPa}$ ) are more significant. This fact means that non-convective clouds at the low altitude in the GR scheme increased compared to those in the new scheme. In this trend, shallow diluted convection is considered to transport moisture to the region of non-convective clouds, as seen in Fig. 12 (drying rate from convective clouds at $800 \mathrm{hPa}$ height of GR scheme is less significant compared to that of the new scheme, see also Fig. 9 where the GR scheme showed moistening trends at $900 \mathrm{mb}$ level).

The differences in the convective structures are considered to be derived from entrainment and detrainment profiles of convective updraft. Figure 13 shows meridional mean vertical profiles of entrainment and detrainment. Since the GR scheme could not consider the decrease of entrainment by the detrainment, the entrainment (not 'entrainment rate') tends to excessively increase in lower altitude and even in upper altitude where the detrainment is dominant. These trends cause excessive entrainment of environmental air into convective clouds, leading to too much formation of diluted convective and non-convective clouds in the low altitude, and less formation of strong deeper clouds. These trends eventually may cause some differences in the precipitation and radiative properties.

Zonal mean vertical profiles of temperature and moisture were evaluated using ERA-interim (Dee et al. 2011), as shown in Fig. 14. Warm biases are apparent at the upper atmosphere, but these are common for both cases and are considered to derive from other physical parameterizations. Otherwise, temperature profiles show good agreement with the reanalysis data. In contrast to the temperature trends, a large negative humidity bias is observed in the GR scheme at the equator in low to middle altitudes. This may be caused by the scheme computing excessive consumption or dilution of humidity in this region, originating from too much entrainment in the low altitudes as shown in Fig. 13.

The simulated annual mean precipitation is validated by comparing the results with CPC Merged Analysis of Precipitation (CMAP) data (Xie and Arkin 1997) in Fig. 15. In the results, neither scheme showed unrealistic double Intertropical Convergence Zone (ITCZ) trends (e.g., Bellucci et al. 2010). The most prominent difference between the GR scheme and the new scheme is the precipitation pattern in the western Pacific region, where the new scheme

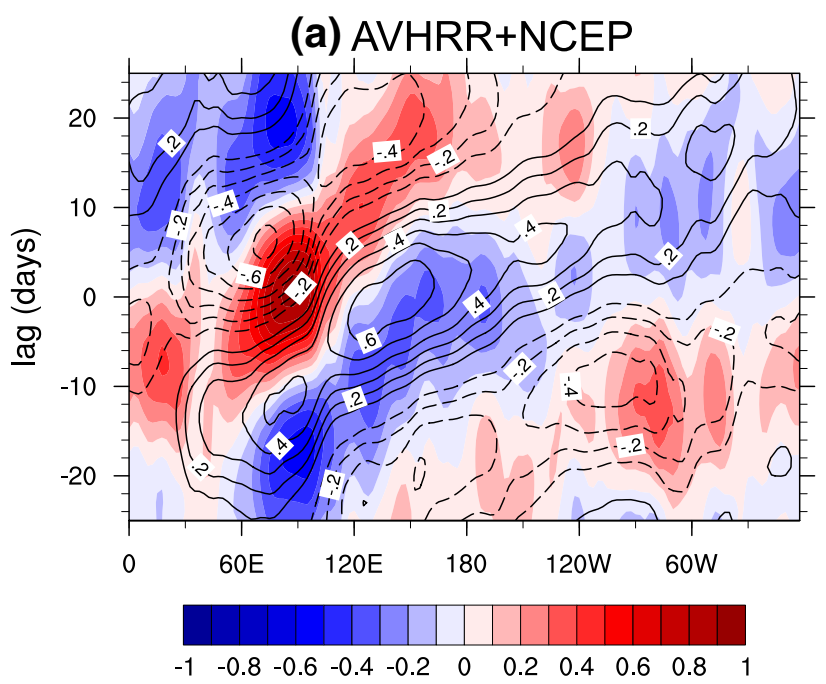

(b) GR scheme

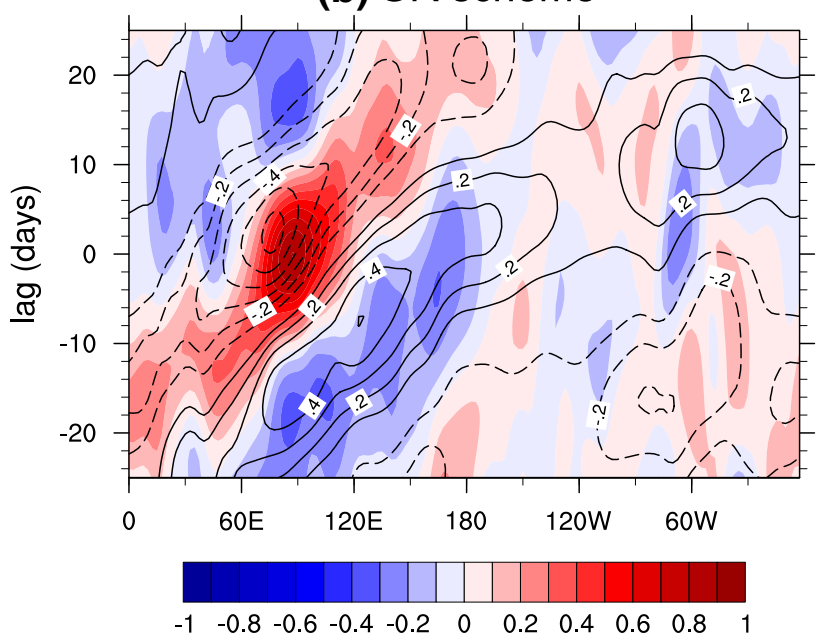

(c) New scheme

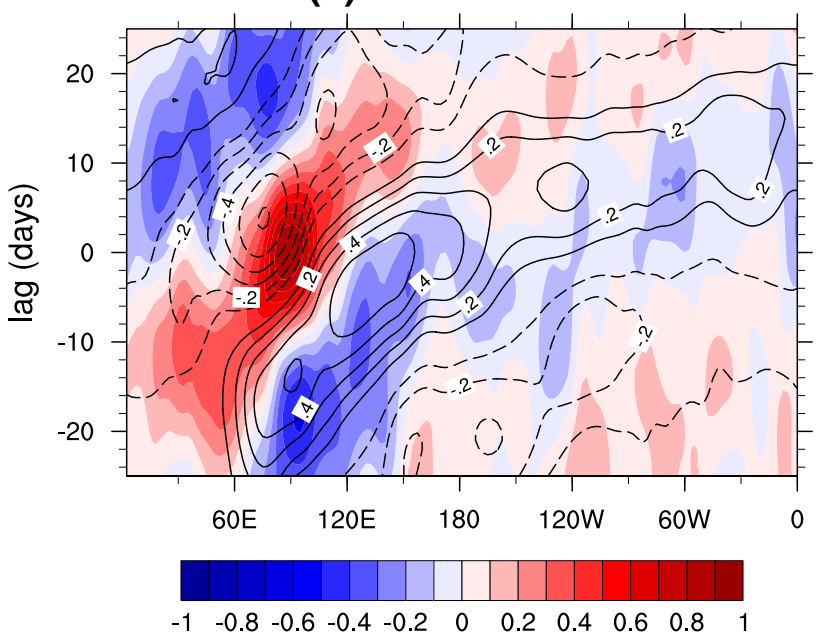

Fig. 17 Lag-cross-correlation for $10^{\circ} \mathrm{S}-10^{\circ} \mathrm{N}$ averaged OLR (shade) and zonal wind (contour, $\mathrm{m} \mathrm{s}^{-1}$ ) at $850 \mathrm{hPa}$ anomalies. The lag-crosscorrelation is computed for all seasons and over the 7 years 
Fig. 18 Coherence-squared (shade) and phase lag (vectors) between OLR and zonal wind at $850 \mathrm{hPa}$ over the 7 years.

The vectors represent phase lag between OLR and zonal wind as upward: zero phase lag, downward: out of phase, rightward:

OLR leads zonal wind, and leftward: OLR lags zonal wind

\section{(a) AVHRR+NCEP}
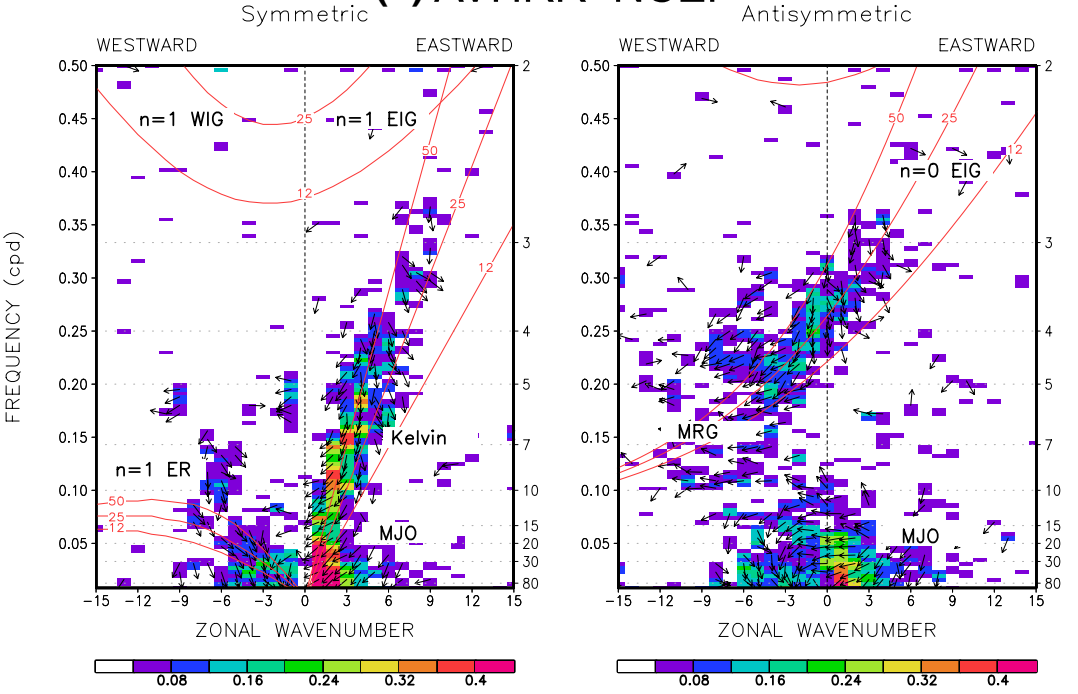

(b) GR scheme
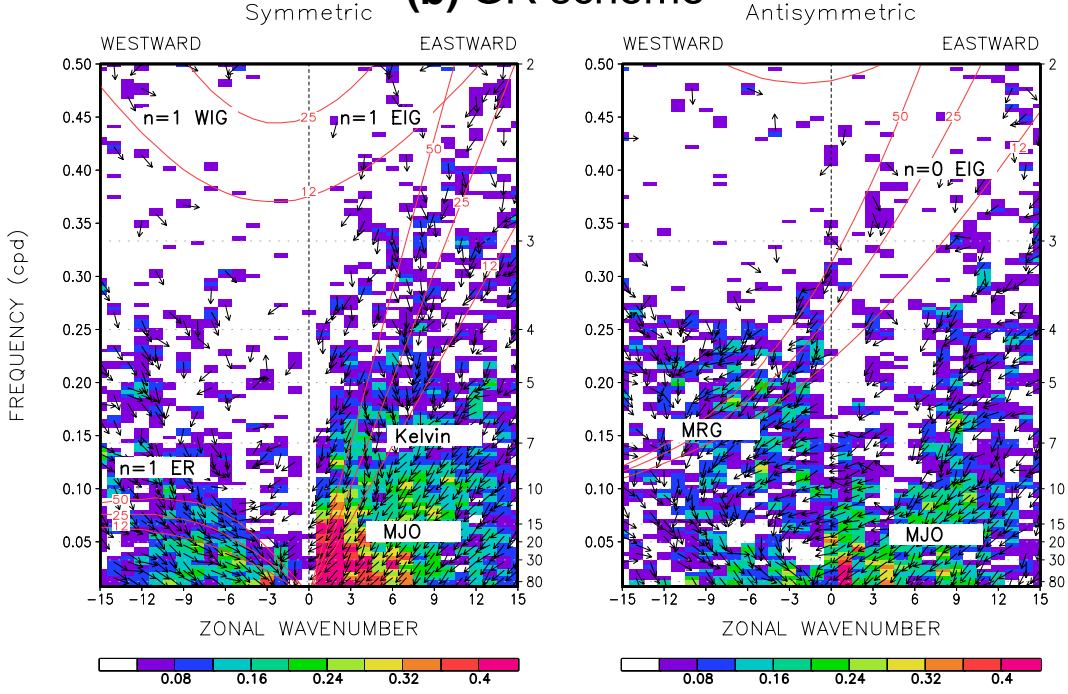

(c) New scheme
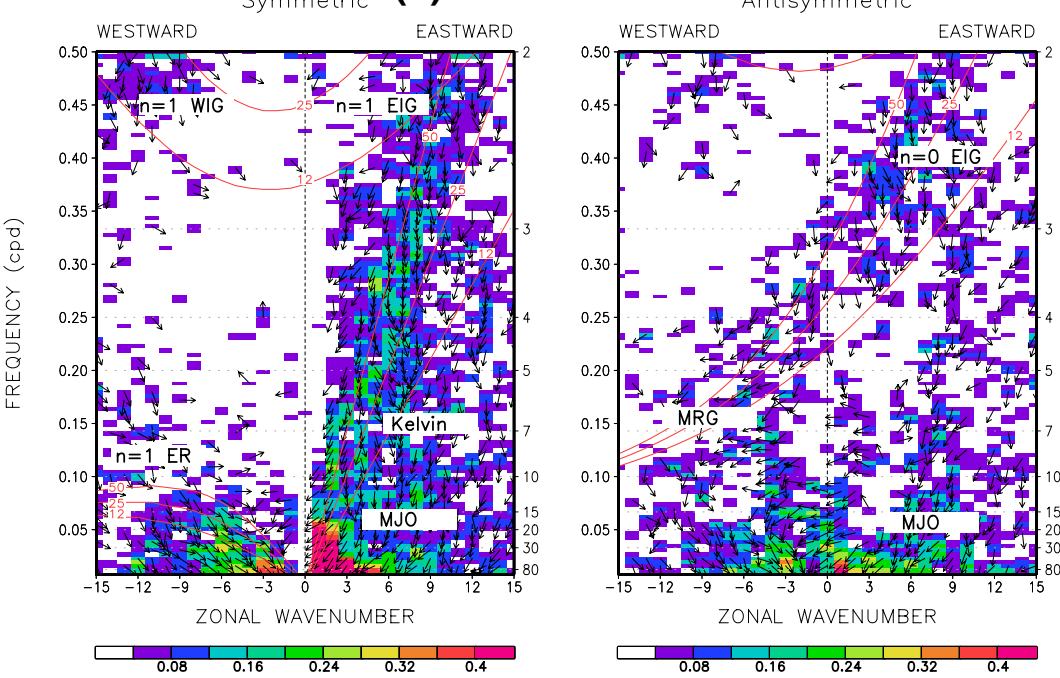
improved positive precipitation bias compared with the GR scheme. Both schemes present positive precipitation bias in high latitude regions, but the bias is considered to be derived from non-convective cloud scheme since the non-convective precipitation is dominant in the high latitude regions (as shown also in Fig. 15).

Radiative properties from model results were analyzed using Clouds and the Earth's Radiant Energy System, Energy Balanced and Filled (CERES-EBAF) satellite data (Loeb et al. 2009), as in Fig. 16. The biases in outgoing long wave radiation (OLR) in both cases are different but of similar magnitude, and a clear difference is not observed from the annual mean state. A significant difference is seen in the outgoing shortwave radiation (OSR) trends, where the new scheme greatly improves positive bias of the OSR over the ocean. This is considered to be derived from the difference in cloud condensate at low altitude, since low-level clouds are known to have high albedo due to small effective radius of cloud droplets (e.g., Baba 2015). As noted above, low-level nonconvective clouds are more significant in the GR scheme, because weak diluted updraft that enhanced formation of the low-level clouds was simulated by the scheme. It can be therefore concluded that the large OSR bias in the GR scheme is originated from the low-level clouds trends.

\subsection{Variability}

Further analysis on the variability of atmospheric circulation, especially intraseasonal variability, was performed using US CLIVAR MJO diagnostics (Waliser et al. 2011). To conduct comparison with observation, Advanced Very High Resolution Radiometer (AVHRR, Liebmann and Smith 1996) OLR and daily wind data of NCEP-NCAR reanalysis (Kalnay et al. 1996) were used in the following analysis.

Lag-cross-correlation diagrams for OLR and zonal wind anomalies are compared in Fig. 17. The comparison indicates that the results of both schemes are in good agreement with the trend of reanalysis data, although the lag of zonal wind to OLR is slightly shorter than the reanalysis data. The lag-cross-correlation captured clear signals for periodical appearance and cycle of intraseasonal variability in both the OLR and zonal wind anomalies as indicated by reanalysis data, and the signal propagates eastward with a similar propagation speed. The trends suggested that the both schemes can simulate essential features of MJO, especially, the features in terms of spontaneous generation with its reasonable cycle and eastward movement.

The features of simulated CCEWs and MJO were validated using space-time spectral analysis. Figure 18 shows the coherence-squared and phase between equatorial OLR and zonal wind at $850 \mathrm{hPa}$. In the symmetric spectrum, although high coherence-squared of model results is spread
Fig. 19 Comparison of composite life cycle of MJO over 7 years. 20-100 day band pass filtered OLR (shade, unit: $\mathrm{W} \mathrm{m}^{-2}$ ), zonal and meridional winds at $850 \mathrm{hPa}$ anomalies (vectors) are used

wider than the reanalysis data, the both schemes captured MJO, which is defined as the spectral components within zonal wavenumbers $1-3$, and period of $30-80$ days. It is apparent from comparisons that the spectrum of the new scheme is closer to the reanalysis than the GR scheme, and qualitative trends of the lags of zonal wind to OLR are reproduced. Moreover, the GR scheme simulated a much more unrealistic westward propagating component, and the Kelvin wave became obscure in comparison to the new scheme. This trend is consistent with the trend of increased low-level clouds in the GR scheme as seen in the mean state, since such increase in the westward spectral component relates to an increase of low-level clouds (weak convective and nonconvective) moving westward along with the trade wind in the equatorial region. In addition to the improvement in the symmetric spectrum, the new scheme improves mixed Rossby-gravity wave trends in the asymmetric spectrum as compared with the GR scheme.

Finally, the composite life cycle of MJO was evaluated using band-pass filtered OLR, zonal and meridional winds at $850 \mathrm{hPa}$ (Fig. 19). The comparison of the life cycle apparently showed that the both schemes could simulate generation and eastward propagation of MJO. However, the intensity of MJO represented by OLR anomalies is different, i.e., the intensity simulated by new scheme is moderate and closer to reanalysis than the GR scheme, which simulated too strong intensity. Hirons et al. (2013) described that cumulus congestus increase due to the resulting effect of dry air entrainment caused by modified cumulus parameterization could improve MJO simulation. They noted that cumulus congestus moistened mid-troposphere and the effect dominated MJO behavior. Since GR scheme tends to increase low-level entrainment and thus causes diluted convection, it can be assumed that similar improvement can be obtained also by the GR scheme. However, the situation is different and the difference can be found from the moistening profiles of convective and non-convective clouds (see Fig. 12). The moistening at the mid-troposphere was not enhanced by both convective and non-convective clouds, and drying became significant only in the low-level. This may be derived from the fact that cumulus congestus did not increase by the increase of dry air entrainment in GR scheme, and most of the moisture was consumed by the formation of low-level clouds since moisture transport was limited to low altitudes due to the weakened convection. Shallow convection is known to play important roles in simulating MJO (e.g., Zhang and Song 2009; Hung et al. 2013), but since the GR scheme overestimated low-level 


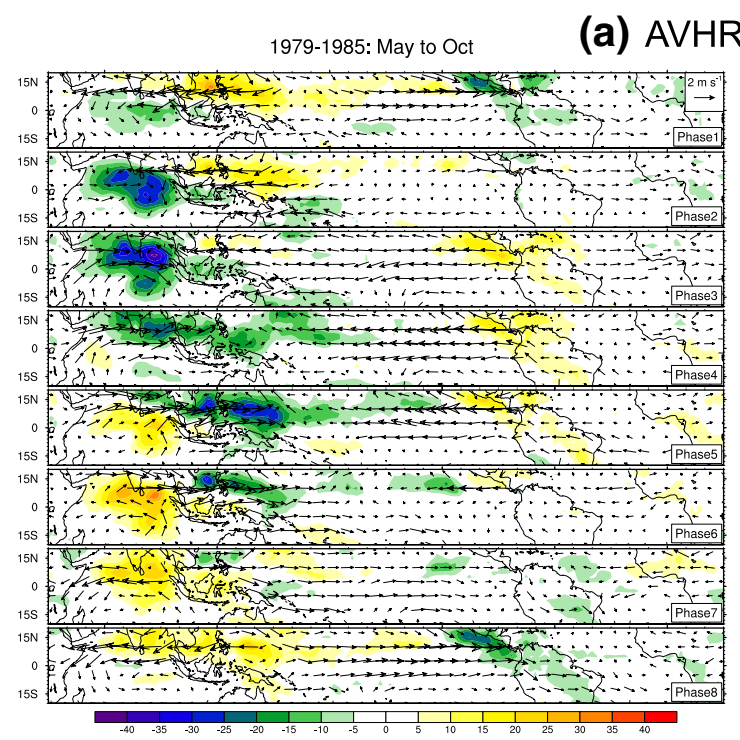

1979-1985: Nov to Apr

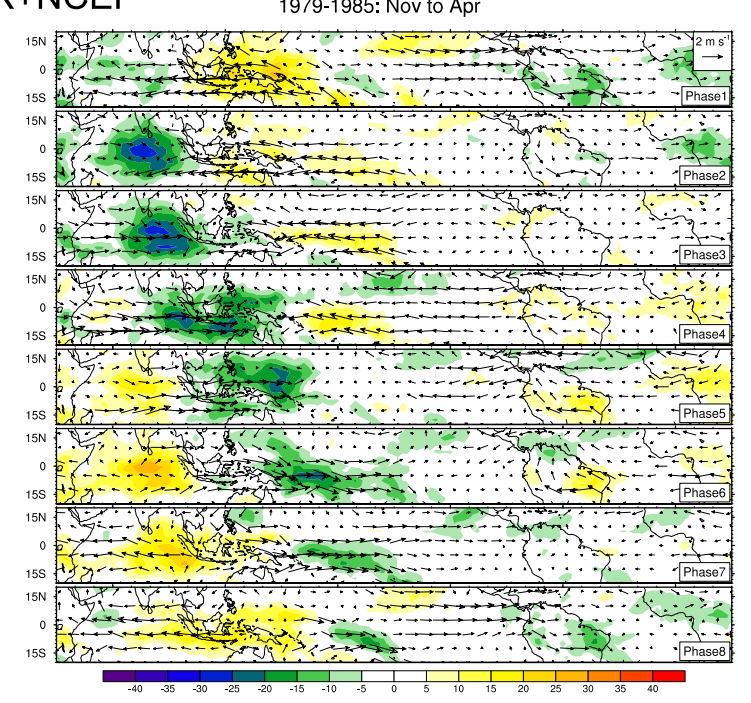

(b) GR scheme
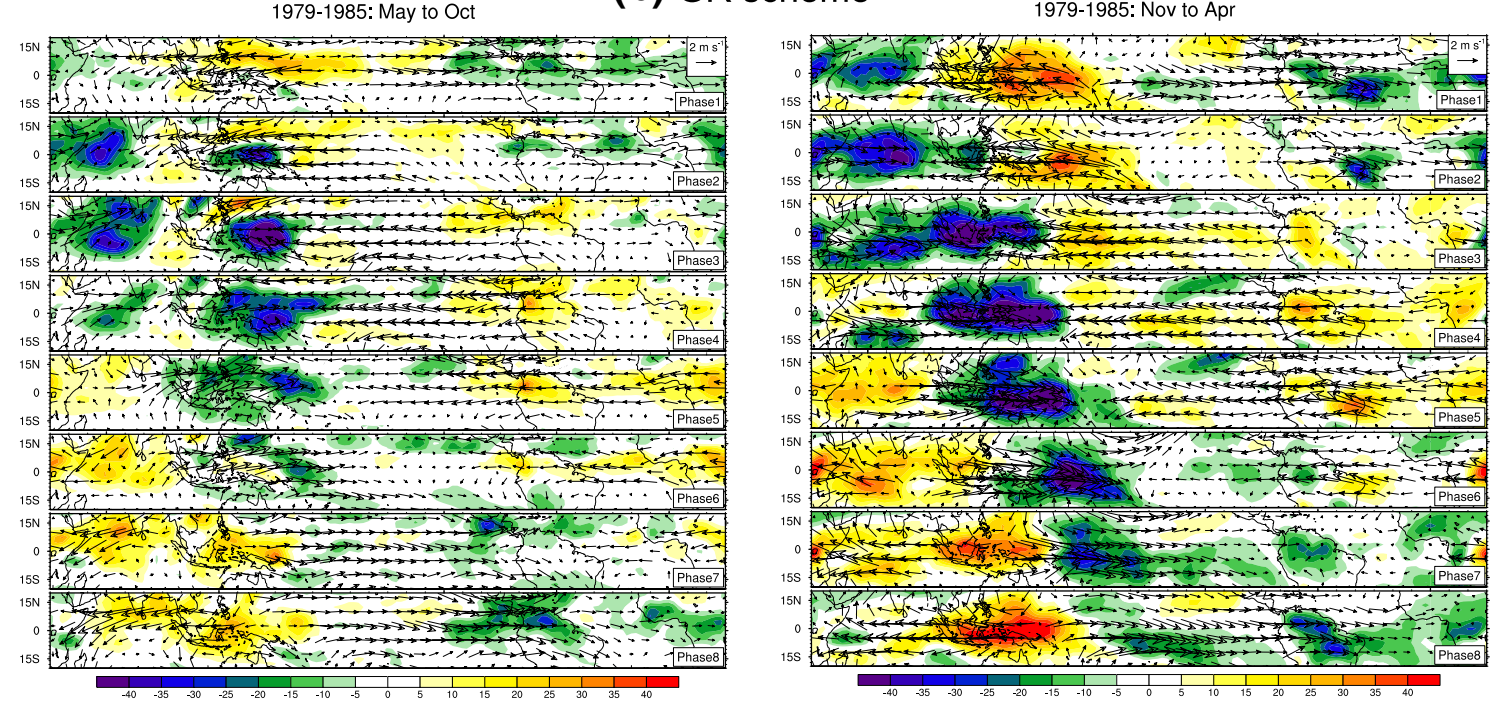

1979-1985: May to Oct

(c) New scheme
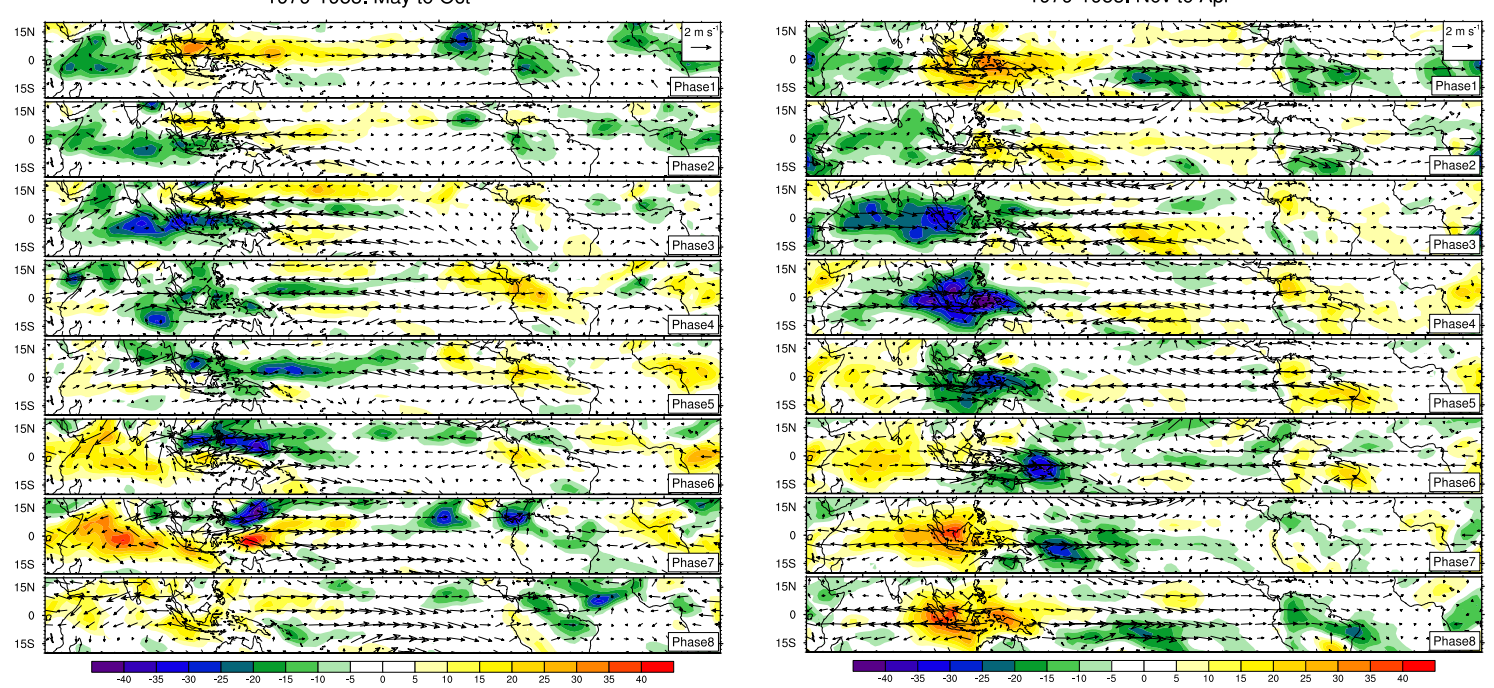
entrainment and thus simulated too much low-level clouds, the GR scheme is considered to overestimate the intensity of MJO.

\section{Summary and conclusion}

A spectral cumulus parameterization employing new incloud parameterization was proposed based on findings for the statistical in-cloud properties obtained from a cloudresolving model (CRM) simulation. Features of the developed parameterization were first examined in SCM experiment. The scheme was subsequently assessed in an AGCM using an AMIP experiment.

Long-range CRM simulation was used to estimate statistical in-cloud properties and their relationship. The results showed that entrainment was dominant in the lower altitudes, while detrainment was dominant in the higher altitudes. The change in entrainment term of the cloud updraft velocity equation was found that it could not be expressed only by the variation of buoyancy. The detrainment term was found to have impact on the buoyancy variation and thus also was expected to have impact on the variation of entrainment term. Considering the effect of detrainment on the buoyancy, a consistent equation for entrainment rate that can be applied for both deep and shallow convection was introduced. Considering this modification for entrainment rate, the cloud mean updraft velocity equation was modified so the formulation could account for the effect of detrainment.

A cumulus parameterization was constructed using relevant existing parameterizations and the proposed formulations for entrainment rate. To consider the coexistence of deep and shallow convection, the parameterization was based on a spectral approach rather than a bulk mass flux approach.

SCM experiments were performed to examine basic features of the developed cumulus parameterization (new scheme), and the results were compared with those from a cumulus parameterization employing the entrainment model of Gregory (2001) (GR scheme). The comparisons showed that convective clouds simulated with the GR scheme became shallower and more diluted due to larger entrainment.

The cumulus parameterizations were implemented into an AGCM, and AMIP experiments were performed. The results from the new scheme were compared with those obtained from the GR scheme, and validated with reanalysis data. The new scheme showed improvements in both the mean state and variability of the simulated global atmospheric circulation, i.e., the new scheme improved positive precipitation bias in the western Pacific region and improved positive OSR bias over the ocean, and also simulated better features of CCEW, and MJO with moderate strength. The improvement was found to derive mainly from differences in the simulated entrainment profile. The GR scheme tended to simulate an excessive increase of entrainment in the low altitudes, resulting in enhancing shallow diluted and low-level non-convective clouds; similar features were found in the SCM experiments. In contrast, the new scheme suppressed the excess of entrainment and thus suppressed unrealistic increase of low-level clouds.

In conclusion, the developed parameterization employing new in-cloud parameterization for entrainment rate can improve some biases of the existing parameterization. The proposed cumulus parameterization is not perfect, and thus further studies might be required for further improvement. For example, convective closure of the parameterization may need improvement so that the parameterization can simulate accurate diurnal cycle over continents (e.g., Bechtold et al. 2014). In addition, to determine coefficients of entrainment, more realistic long-range CRM experiment (e.g., TOGACOARE experiment, Wu et al. 1998) might be beneficial since the present study is based on an idealized long-range CRM simulation.

The pilot version code of this cumulus parameterization is available under MIT license at https://gitlab.com/babay/ cumulus.

Acknowledgements This work was supported by the Japan Society for the Promotion of Science, Grant-in-Aid for Scientific Research (C), Grant number 16K05559.

Open Access This article is distributed under the terms of the Creative Commons Attribution 4.0 International License (http://creativeco mmons.org/licenses/by/4.0/), which permits unrestricted use, distribution, and reproduction in any medium, provided you give appropriate credit to the original author(s) and the source, provide a link to the Creative Commons license, and indicate if changes were made.

\section{Appendix 1: Discretization of updraft budget equations}

The updraft budget equations are integrated fractionally, because microphysical term and lateral exchange terms (e.g., entrainment and detrainment) cannot be evaluated simultaneously. At the cloud base, a saturation adjustment is performed, and the cloud base in-cloud buoyancy is calculated. Then, entrainment rate at the cloud base can be estimated using Eq. (10) without detrainment. The updraft quantities are integrated upward using entrainment and microphysical terms as:

$$
\begin{aligned}
& \left(M_{u}\right)_{k+1 / 2}^{*}=\left(M_{u}\right)_{k-1 / 2}+\Delta z_{k}\left(\epsilon_{u} M_{u}\right)_{k-1 / 2}, \\
& \left(M_{u} \phi_{u}\right)_{k+1 / 2}^{*}=\left(M_{u} \phi_{u}\right)_{k-1 / 2}+\Delta z_{k}\left(\epsilon_{u} M_{u}\right)_{k-1 / 2} \bar{\phi}_{k}+\Delta z_{k}\left(S_{\phi}\right)_{k},
\end{aligned}
$$


where $\Delta z_{k}$ is the layer thickness at level $k, \phi$ represents diagnostic variables in cumulus parameterization, and $\phi_{u}$ represents in-cloud quantities. Here, superscript $j$ representing $j$-th cloud type is omitted for simplicity, and will be omitted hereafter. $S_{\phi}$ is the microphysical source (sink) term. Using fractionally integrated quantities without effect of detrainment, the updraft detrainment rate based on Eq. (13) can be calculated as:

$\left(\delta_{u}\right)_{k}=-R_{\text {det }}\left(\frac{\partial \ln \theta_{v}^{\prime}}{\partial z}\right)_{* k} \approx-R_{\text {det }} \frac{\left(\theta_{v}^{\prime}\right)_{* k+1 / 2}-\left(\theta_{v}^{\prime}\right)_{* k-1 / 2}}{\left(\theta_{v}^{\prime}\right)_{* k} \Delta z_{k}}$.

The detrainment terms are evaluated and upper half level values are obtained as:

$\left(M_{u}\right)_{k+1 / 2}=\left(M_{u}\right)_{k+1 / 2}^{*}-\Delta z_{k}\left(\delta_{u}\right)_{k}\left(M_{u}\right)_{k+1 / 2}^{*}$,

$\left(M_{u} \phi_{u}\right)_{k+1 / 2}=\left(M_{u} \phi_{u}\right)_{k+1 / 2}^{*}-\Delta z_{k}\left(\delta_{u}\right)_{k}\left(M_{u} \phi_{u}\right)_{k+1 / 2}^{*}$.

When cloud mean updraft velocity becomes negative, the height is defined as the cloud top. In this case, cloud mass flux detrains completely at the cloud top layer and the detrainment rate is set to $1 / \Delta z_{k}$.

\section{Appendix 2: Discretization of cloud mean updraft velocity equation}

The cloud mean updraft velocity equation of Eq. (12) is discretized as:

$\frac{1}{2} \frac{\left(w_{u}^{2}\right)_{k+1 / 2}-\left(w_{u}^{2}\right)_{k-1 / 2}}{\Delta z_{k}}=a_{n}\left(B_{u}\right)_{k}-b_{n} \frac{\left(w_{u}^{2}\right)_{k+1 / 2}+\left(w_{u}^{2}\right)_{k-1 / 2}}{2}$.

The value of $w_{u}^{2}$ at the cloud base is presumed, and in-cloud buoyancy $B_{u}$ is calculated after the budget equation is evaluated. Equation (44) is solved for $\left(w_{u}^{2}\right)_{k+1 / 2}$ and the upper limit value of $w_{u}$ is set to $15 \mathrm{~m} \mathrm{~s}^{-1}$ during its vertical integration. Using upper half level values of $w_{u}$ and $B_{u}$, the upper half level value of updraft entrainment rate $\epsilon_{u}$ is obtained as:

$\left(\epsilon_{u}\right)_{k+1 / 2}=\frac{C_{1}\left(B_{u}\right)_{k+1 / 2}-C_{2}\left(\delta_{u}\right)_{k+1 / 2}\left(w_{u}^{2}\right)_{k+1 / 2}}{\left(w_{u}^{2}\right)_{k+1 / 2}}$,

where $\left(\delta_{u}\right)_{k+1 / 2}=2\left(\delta_{u}\right)_{k}-\left(\delta_{u}\right)_{k-1 / 2}$, i.e., the upper half level value of $\delta_{u}$ is obtained from full level value and lower half level value. The value of $\delta_{u}$ at the cloud base is set to zero.

\section{Appendix 3: Discretization of downdraft budget equations}

The convective downdraft starts from LFS height and so the cloud mass flux at the LFS height is calculated by:
$\left(M_{d}\right)_{k}=-\eta_{d} M_{b}, \quad\left(M_{d} \phi_{d}\right)_{k}=\left(M_{d}\right)_{k} \phi_{L F S}$,

where $\phi_{\text {LFS }}$ represent diagnostic variables in the cumulus parameterization that are obtained from the average of cloud mean value and the environmental value, i.e., $\phi_{L F S}=\left[\phi_{u}\left(z_{L F S}\right)+\bar{\phi}\left(z_{L F S}\right)\right] / 2$. After the saturation adjustment for evaporation of precipitation within the downdraft and calculation of downdraft entrainment rate, the downdraft entrainment is used to integrate downdraft quantities downward as:

$\left(M_{d}\right)_{k-1}^{*}=\left(M_{d}\right)_{k}+\Delta z_{k}\left(\epsilon_{d} M_{d}\right)_{k}$,

$\left(M_{d} \phi_{d}\right)_{k-1}^{*}=\left(M_{d} \phi_{d}\right)_{k}+\Delta z_{k}\left(\epsilon_{d} M_{d}\right)_{k} \bar{\phi}_{k}+\Delta z_{k}\left(S_{\phi}\right)_{k}$.

Note that $\epsilon_{d}$ contains organized and turbulent entrainment rates. Then, downdraft detrainment is evaluated as:

$\left(M_{d}\right)_{k-1}=\left(M_{d}\right)_{k-1}^{*}-\Delta z_{k}\left(\delta_{d}\right)_{k}\left(M_{d}\right)_{k-1}^{*}$,

$\left(M_{d} \phi_{d}\right)_{k-1}=\left(M_{d} \phi_{d}\right)_{k-1}^{*}-\Delta z_{k}\left(\delta_{d}\right)_{k}\left(M_{d} \phi_{d}\right)_{k-1}^{*}$.

The downdraft calculation is repeated until $M_{d}$ reaches zero. Note that negative buoyancy caused by evaporation (sublimation) of precipitation is dominant force for downdraft, so the evaporation must be computed simultaneously with the downdraft calculation.

\section{Appendix 4: Diagnostic convective closure}

The diagnostic convective closure scheme (Bechtold et al. 2014) is applied to calculate the cloud base mass flux of each cloud type. The scheme employs a density-weighted CAPE instead of normal CAPE, given by:

$P C A P E=g \int_{z_{b}}^{z_{t}} \frac{T_{v, u}-\bar{T}_{v}}{\bar{T}_{v}} \bar{\rho} d z$.

Assuming PCAPE is consumed within time scale of $\tau$, the diagnostic cloud base mass flux is obtained as:

$M_{b}=\frac{P C A P E}{\tau} \frac{M_{b}^{*}}{\int_{z_{b}}^{z_{t}} g / \bar{T}_{v}\left(\partial \bar{T}_{v} / \partial z+g / c_{p}\right) M^{*} d z}$,

where $M_{b}^{*}$ and $M^{*}$ are provisional cloud base mass flux and cloud mass flux, respectively. The convection time scale $\tau$ follows Bechtold et al. (2014). Note that the diagnostic closure is applied to all the cloud types, and more appropriate closure for shallow convection should be discussed in the future study. 


\section{Appendix 5: Bulk updraft mean properties, cloud base height and sub-cloud layer}

The bulk updraft mean properties are necessary to compute convective downdraft and tendencies to environment. The bulk updraft mean value of certain in-cloud quantities can be obtained by (e.g., Nordeng 1994):

$\phi_{u}=\frac{\sum_{j} \alpha^{j} M_{u}^{j} \phi_{u}^{j}}{\sum_{j} \alpha^{j} M_{u}^{j}}$,

where $\alpha^{j}$ is the weighting factor for $j$-th cloud type, $\phi_{u}^{j}$ is the updraft in-cloud variable for $j$-th cloud type, $\phi_{u}$ is its bulk updraft mean value, and $M_{u}^{j}$ is the updraft cloud mass flux for $j$-th cloud type.

The calculation of cloud base height follows Tiedtke (1989). The air parcel at the lowest model level is lifted as dry adiabatic ascent, and if the air parcel is saturated, then the air parcel is lifted as moist adiabatic ascent. When the condition of the air parcel satisfies moistly saturated and the air parcel has temperature higher than $-0.5 \mathrm{~K}$ compared to the environment, the height is defined as the cloud base height.

The calculation of the sub-cloud layer below the cloud base basically follows ECMWF (2014). The in-cloud quantities in the sub-cloud layer are given as:

$$
\begin{aligned}
& \left(M_{u}\right)_{k-1 / 2}=Z_{k-1 / 2}^{m} M_{b}, \quad Z_{k-1 / 2}=\frac{z_{k-1 / 2}-z_{g}}{z_{\text {base }}-z_{g}}, \\
& \left(M_{u} \phi_{u}\right)_{k-1 / 2}=Z_{k-1 / 2}^{m} M_{b} \phi_{\text {base }},
\end{aligned}
$$

where $z_{g}$ is the height of ground surface and $m=1$. $\phi_{u}$ is the diagnostic variables for the updraft excluding cloud condensate. The subscript base indicates the value is at the cloud base, and the quantities are obtained from moist adiabatic ascent used in determining the cloud base height.

\section{Appendix 6: Pressure gradient term in convective momentum transport}

When the convection occurs, horizontal momentum is transported vertically. This effect is known as convective momentum transport (CMT). The pressure gradient force on the CMT was originally developed by Zhang and Cho (1991a, b); Wu and Yanai (1994) (and was examined by Zhang and Wu 2003). Gregory et al. (1997) empirically modeled the pressure gradient force on CMT as:

$\mathbf{P}_{\mathbf{u}}^{j}=C_{u} M_{u}^{j} \frac{\partial \overline{\mathbf{v}}}{\partial z}, \quad \mathbf{P}_{\mathbf{d}}=C_{d} M_{d} \frac{\partial \overline{\mathbf{v}}}{\partial z}$, where $C_{u}$ and $C_{d}$ are the model parameters representing strength of pressure gradient on the CMT. Gregory et al. (1997) suggested $C_{u}=C_{d}=0.7$, however, recent studies indicated that the effect of pressure gradient is much smaller than the values, and $C_{u}=C_{d}=0$ produced better results (e.g., Richter and Rasch 2008; Romps 2012). Following these findings, the values of coefficients are set to zero in the present study.

\section{Appendix 7: Implicit time integration}

The tendencies from the convective updraft and downdraft can be written in a general form as:

$\bar{\rho} \frac{\partial \bar{\phi}}{\partial t}=-\frac{\partial}{\partial z}\left[M_{u} \phi_{u}+M_{d} \phi_{d}-\left(M_{u}+M_{d}\right) \bar{\phi}\right]+\bar{\rho} S_{\phi}$,

where $S_{\phi}$ is the source term for the environmental value $\bar{\phi}$. The above equation can be transformed into:

$\bar{\rho} \frac{\partial \bar{\phi}}{\partial t}-\left(M_{u}+M_{d}\right) \frac{\partial \bar{\phi}}{\partial z}=\bar{\rho} S_{\phi}^{\prime}$,

where $\bar{\rho} S_{\phi}^{\prime}$ contains the original source terms and detrainment terms. Equation (58) corresponds to vertical advection equation including source terms. Assuming $w=-\left(M_{u}+M_{d}\right) / \bar{\rho}$, upwind biased discretization of Eq. (58) is given as:

$$
\begin{gathered}
\frac{\phi_{k}^{*}-\phi_{k}}{\Delta t}+w_{k}\left(\frac{-\phi_{k-1}^{*}+\phi_{k}^{*}}{2 \Delta z_{k-1 / 2}}+\frac{-\phi_{k}^{*}+\phi_{k+1}^{*}}{2 \Delta z_{k+1 / 2}}\right) \\
+\left|w_{k}\right|\left(\frac{-\phi_{k-1}^{*}+\phi_{k}^{*}}{2 \Delta z_{k-1 / 2}}-\frac{-\phi_{k}^{*}+\phi_{k+1}^{*}}{2 \Delta z_{k+1 / 2}}\right)+S_{\phi}^{\prime},
\end{gathered}
$$

where $\phi^{*}$ is the predicted value. Equation (59) can be regarded as the tri-diagonal matrix for $\phi^{*}$, and can be solved with tri-diagonal matrix algorithm without any iteration. Equation (58) is non-conservative form to simply the solution and to ensure numerical stability, and any correction methods are not used here. Time integration with conservative form such as Yoshimura et al. (2015) should be discussed in the future study.

\section{Appendix 8: Cloud microphysics}

The cloud microphysics that describes water conversion within convective clouds follow ECMWF (2014). Condensation (deposition) of cloud condensate is calculated in the convective updraft based on the saturation adjustment which is given as:

$\bar{\rho} c_{u}=\frac{q_{u}-q_{s a t}\left(T_{u}, \bar{p}\right)}{1+\left.\frac{L}{c_{p}} \frac{\partial q_{s a t}}{\partial T}\right|_{T=T_{u}}} \frac{M_{u}}{\Delta z}$,

where $c_{p}$ is the specific heat at constant pressure, $q_{s a t}$ is the saturation specific humidity and is a function of temperature 
and pressure. The freezing rate of cloud condensate is set so that the ice fraction would not fall below $\eta(\bar{T})$, and is given as:

$\bar{\rho} f_{u}=\left[\eta(\bar{T}) l_{u}-i_{u}\right] \frac{M_{u}}{\Delta z}$,

where $\bar{\rho} f_{u} \geq 0$. The generation rate of precipitation is modeled by Sundqvist et al. (1989) as:

$\bar{\rho} G_{p}=\frac{c_{0} M_{u} l_{u}}{w_{u}}\left[1-\exp \left(\frac{l_{u}}{l_{c r i t}}\right)^{2}\right]$,

where $c_{0}=1.8 \times 10^{-3} \mathrm{~s}^{-1}$ and $l_{\text {crit }}=0.5 \mathrm{~g} \mathrm{~kg}^{-1}$ is the critical cloud condensate. The critical value of cloud condensate has dependence on temperature with consideration for the Bergeron-Findeisen process for cold temperature. In the convective downdraft, following evaporation of precipitation is considered:

$\bar{\rho} e_{d}=\frac{q_{s a t}\left(T_{d}, \bar{p}\right)-q_{d}}{1+\left.\frac{L}{c_{p}} \frac{\partial q_{s a t}}{\partial T}\right|_{T=T_{d}}} \frac{M_{d}}{\Delta z}$.

In the calculation of $e_{d}$, condensation (deposition) of precipitation is not allowed. Since Eq. (63) represents evaporation of total precipitation, snow sublimation is considered by partitioning the evaporation using the ice fraction. Direct evaporation to the environmental air is activated only below the cloud base. The evaporation (sublimation) of precipitation follows the work of Kessler (1995) and is given as:

$\tilde{e}_{p}=C_{c} \alpha_{1}\left[R H q_{s a t}(\bar{T}, \bar{p})-\bar{q}\right]\left[\frac{P \sqrt{\bar{p} / \bar{p}_{s}}}{\alpha_{2} C_{c}}\right]^{\alpha_{3}}$,

where $C_{c}=0.05$ is the area fraction of convective cloud, $R H=0.8$ the critical relative humidity, $\bar{p}_{s}$ the surface pressure. Other coefficients are given as $\alpha_{1}=5.44 \times 10^{-4}$, $\alpha_{2}=5.09 \times 10^{-3}$, and $\alpha_{3}=0.5777$.

\section{References}

Arakawa A, Schubert WH (1974) Interaction of a cumulus cloud ensemble with the large-scale environment, Part I. J Atmos Sci 31:674-701

Baba Y (2015) Sensitivity of the atmospheric energy budget to two-moment representation of cloud physics in idealized simulations of convective radiative quasi-equilibrium. Q J R Meteorol Soc 141:114-127

Baba Y (2016) Response of rainfall to land surface properties under weak wind shear conditions. Atmos Res 182:335-345

Baba Y, Takahashi K (2013) Weighted essentially non-oscillatory scheme for cloud edge problem. Q J R Meteorol Soc 139:1374-1388

Baba Y, Takahashi K (2014) Dependency of stratiform precipitation on a two-moment cloud microphysical scheme in mid-latitude squall line. Atmos Res 138:394-413
Baba Y, Takahashi K, Sugimura T, Goto K (2010) Dynamical core of an atmospheric general circulation model on a Yin-Yang grid. Mon Weather Rev 138:3988-4005

Bechtold P, Köhler M, Jung T, Francisco DR, Leutbecher M, Rodwell MJ, Vitart F, Balsamo G (2008) Advances in simulating atmospheric variability with the ECMWF model: from synoptic to decadal time-scales. Q J R Meteorol Soc 134:1337-1351

Bechtold P, Semane N, Lopez P, Chaboureau JP, Beljaars A, Bormann N (2014) Representing equilibrium and nonequilibrium convection in large-scale models. J Atmos Sci 71:734-753

Bellucci A, Gualdi S, Navarra A (2010) Double-ITCZ syndrome in coupled general circulation models: the role of large-scale vertical circulation regimes. J Clim 23:1127-1145

Bretherton CS, McCaa JR, Grenier H (2004) A new parameterization for shallow cumulus convection and its application to marine subtropical cloud-topped boundary layers. Part I: description and 1D results. Mon Weather Rev 132:864-882

Chikira M, Sugiyama M (2010) A cumulus parameterization with statedependent entrainment rate. Part I: description and sensitivity to temperature and humidity profiles. J Atmos Sci 67:2171-2193

Ciesielski PE, Johnson RH, Haertel PT, Wang J (2003) Corrected TOGA COARE sounding humidity data: impact on diagnosed properties of convection and climate over the warm pool. J Clim $16: 2370-2384$

Dawe JT, Austin PH (2011) The influence of the cloud shell on tracer budget measurements of LES cloud entrainment. J Atmos Sci 68:2909-2920

Dee DP et al (2011) The ERA-interim reanalysis: configuration and performance of the data assimilation system. Q J R Meteorol Soc 137:553-597

Del Genio AD, Wu J (2010) The role of entrainment in the diurnal cycle of continental convection. J Clim 23:2722-2738

Del Genio AD, Yao MS, Jonas J (2007) Will moist convection be stronger in a warmer climate? Geophys Res Lett 34(L16):703. https://doi.org/10.1029/2007GL030525

Derbyshire SH, Maidens AV, Milton SF, Stratton RA, Willett MR (2011) Adaptive detrainment in a convective parameterization. Q J R Meteorol Soc 137:1856-1871

Dutra E, Balsamo G, Viterbo P, Miranda PMA, Beljaars A, Schar C, Elder K (2010) An improved scheme for the ECMWF land surface model: description and offline validation. J Hydrometeorol 11:899-916

ECMWF (2014) Part IV: physical processes. Official IFS documentation CY41R1. http://www.ecmwf.int/en/forecasts/documentat ion-and-support/changes-ecmwf-model/ifs-documentation. Accessed 17 Feb 2016

Grabowski WW (1998) Toward cloud resolving modeling of largescale tropical circulations: a simple cloud microphysics parameterization. J Atmos Sci 55:3283-3298

Grabowski WW (2006) Indirect impact of atmospheric aerosols in idealized simulations of convective-radiative quasi equilibrium. J Clim 19:4664-4682

Grant ALM, Brown AR (1999) A similarity hypothesis for shallowcumulus transports. Q J R Meteorol Soc 125:1913-1936

Gregory D (2001) Estimation of entrainment rate in simple models of convective clouds. Q J R Meteorol Soc 127:53-72

Gregory D, Rowntree PR (1990) A mass flux convection scheme with representation of cloud ensemble characteristics and stabilitydependent closure. Mon Weather Rev 118:1483-1506

Gregory D, Kershaw R, Inness PM (1997) Parameterization of momentum transport by convection. II: tests in single-column and general circulation models. Q J R Meteorol Soc 123:1153-1183

Hirons LC, Inness P, Vitart F, Bechtold P (2013) Understanding advances in the simulation of intraseasonal variability in ECMWF model. Part II: the application of process-based diagnostics. Q J R Meteorol Soc 139:1427-1444 
Hung MP, Lin JL, Wang W, Kim D, Shinoda T, Weaver SJ (2013) MJO and convectively coupled equatorial waves simulated by CMIP5 climate models. J Clim 26:6185-6214

Kalnay E, Kanamitsu M, Kistler R, Collins W, Deaven D, Gandin L, Iredell M, Saha S, White G, Woollen J, Zhu Y, Leetmaa A, Reynolds R (1996) The NCEP/NCAR 40-year reanalysis project. Bull Am Meteorol Soc 77:437-471

Kessler E (1995) On the continuity and distribution of water substance in atmospheric circulations. Atmos Res 38:109-145

Khairoutdinov MF, Randall DA (2002) Similarity of deep continental cumulus convection as revealed by a three-dimensional cloudresolving model. J Atmos Sci 59:2550-2566

Khairoutdinov MF, Krueger SK, Moeng CH, Bogenschutz PA, Randall DA (2009) Large-eddy simulation of maritime deep tropical convection. J Adv Model Earth Syst. https://doi.org/10.3894/JAMES .2009 .1 .15

Kim D, Sperber K, Stern W, Waliser D, Kang IS, Maloney E, Wang W, Weickmann K, Benedict J, Khairoutdinov M, Lee MI, Neale R, Suarez M, Thayer-Calder K, Zhang G (2009) Application of MJO simulation diagnostics to climate model. J Clim 22:6413-6436

Kuang Z, Bretherton CS (2006) A mass-flux scheme view of a highresolution simulation of a transition from shallow to deep cumulus convection. J Atmos Sci 63:1895-1909

Kuwano-Yoshida A, Enomoto T, Ohfuchi W (2010) An improved PDF cloud scheme for climate simulations. Q J R Meteorol Soc 136:1583-1597

Liebmann B, Smith CA (1996) Description of a complete (interpolated) outgoing longwave radiation dataset. Bull Am Meteorol Soc 77:1275-1277

Loeb NG, Wielicki DRD, Smith GL, Keyes DF, Kato S, Smith NM, Wong T (2009) Toward optimal closure of the earth's top-ofatmosphere radiation budget. J Clim 22:748-766

Lohmann U, Roeckner E (1996) Design and performance of a new cloud microphysics scheme developed for the ECHAM general circulation model. Clim Dyn 12:557-572

Madden RA, Julian PR (1971) Detection of a 40-50 day oscillation in the zonal wind in the tropical Pacific. J Atmos Sci 28:702-708

McFarlane NA (1987) The effect of orographically excited gravity wave drag on the general circulation of the lower stratosphere and troposphere. J Atmos Sci 44:1775-1800

Miller MJ, Beljaars ACM, Palmer TN (1992) The sensitivity of the ECMWF model to the parameterization of evaporation from the tropical oceans. J Clim 5:418-434

Neggers RAJ, Siebesma AP (2002) A multiparcel model for shallow cumulus convection. J Atmos Sci 59:1655-1668

Nordeng TE (1994) Extended versions of the convective parameterization scheme at ECMWF and their impact on the mean and transient activity of the model in the tropics. ECMWF Technical Memorandum

Pan DM, Randall DA (1998) A cumulus parameterization with a prognostic closure. Q J R Meteorol Soc 124:949-981

Park S, Bretherton C (2009) The University Washington shallow convection and moist turbulence schemes and their impact on climate simulations with the community atmosphere model. J Clim 22:3449-3469

Rayner NA, Parker DE, Horton EB, Folland CK, Alexander LV, Rowell DP, Kent EC, Kaplan A (2003) Global analyses of sea surface temperature, sea ice, and night marine air temperature since the late nineteenth century. J Geophys Res 108(D14):4407

Richter JH, Rasch PJ (2008) Effects of convective momentum transport on the atmospheric circulation in the community atmosphere model, version 3. J Clim 21:1487-1499

Romps DM (2010) A direct measure of entrainment. J Atmos Sci 67:1908-1927

Romps DM (2012) On the equivalence of two schemes for convective momentum transport. J Atmos Sci 69:3491-3500
Rooy WC, Bechtold P, Frohlich K, Hohenegger C, Jonker H, Mironov D, Siebesma AP, Teixeira J, Yano JI (2013) Entrainment and detrainment in cumulus convection: an overview. Q J R Meteorol Soc 139:1-19

Scinocca JF (2003) An accurate spectral nonorographic gravity wave drag parameterization for general circulation models. J Atmos Sci 60:667-682

Siebesma AP et al (2003) A large eddy simulation intercomparison study of shallow cumulus convection. J Atmos Sci 60:1201-1219

Siebesma AP, Cuijpers JWM (1995) Evaluation of parametric assumptions for shallow cumulus convection. J Atmos Sci 52:650-666

Simpson J, Wiggert V (1969) Models of precipitating cumulus towers. Mon Weather Rev 97:471-489

Sundqvist H, Berge E, Kristjansson E (1989) Condensation and cloud parameterization studies with a mesoscale numerical weather prediction model. Mon Weather Rev 117:1641-1657

Tiedtke M (1989) A comprehensive mass flux scheme for cumulus parameterization in large-scale models. Mon Weather Rev 117:1779-1800

von Salzen K, McFarlane NA (2002) Parameterization of the bulk effects of lateral cloud-top entrainment in transient shallow cumulus clouds. J Atmos Sci 59:1405-1430

Waliser D, Sperber K, Hendon H, Kim D, Maloney E, Wheeler M, Weickmann K, Zhang C, Donner L, Gottscharck J, Higgins W, Kang IS, Legler D, Moncrieff M, Schubert S, Stern W, Vitart F, Wang B, Wang W (2011) MJO simulation diagnostics. J Clim 22:3006-3030

Weaver SJ, Wang W, Chen M, Kumar A (2011) Representation of MJO variability in the NCEP climate forecast system. J Clim 24:4676-4694

Wu X, Yanai M (1994) Effects of vertical wind shear on the cumulus transport of momentum: observations and parameterization. J Atmos Sci 51:1640-1660

Wu X, Grabowski WW, Moncrieff MW (1998) Long-term behavior of cloud systems in TOGA COARE and their interactions with radiative and surface processes. Part I: two-dimensional modeling study. J Atmos Sci 55:2693-2714

Xie P, Arkin PA (1997) Global precipitation: a 17-year monthly analysis based on gauge observations, satellite estimates, and numerical model outputs. Bull Am Meteorol Soc 78:2539-2558

Xu KM (1995) Partitioning mass, heat, and moisture budgets of explicitly simulated cumulus ensembles into convective and stratiform components. Mon Weather Rev 52:551-573

Yoshimura H, Mizuta R, Murakami H (2015) A spectral cumulus parameterization scheme interpolating between two convective updrafts with semi-lagrangian calculation of transport by compensatory subsidence. Mon Weather Rev 143:597-621

Zhang GJ, Cho HR (1991a) Parameterization of the vertical transport of momentum by cumulus clouds. Part I: theory. J Atmos Sci 48:1483-1492

Zhang GJ, Cho HR (1991b) Parameterization of the vertical transport of momentum by cumulus clouds. Part II: application. J Atmos Sci 48:2448-2457

Zhang GJ, McFarlane NA (1995) Sensitivity of climate simulations to the parameterization of cumulus convection in the Canadian climate centre general circulation model. Atmos Ocean 33:407-446

Zhang GJ, Song X (2009) Interaction of deep and shallow convection is key to Madden-Julian oscillation simulation. Geophys Res Lett. https://doi.org/10.1029/2009GL037340

Zhang GJ, Wu X (2003) Convective momentum transport and perturbation pressure field from a cloud-resolving model simulation. J Atmos Sci 60:1120-1139

Zhang GJ, Wu X, Mitovski T (2016) Estimation of convective entrainment properties from cloud-resolving model simulation during TWP-ICE. Clim Dyn 47:2177-2192 